\title{
Ag20/GO/TiO2 Composite Nanostructure: An Efficient Heterogeneous Catalyst for one Pot Synthesis of Bis (Dihydropyrimidinone) and Tetrahydro-4H-chromenes Derivatives
}

Fatemeh Samandi Zadeh

Islamic Azad University Ahvaz Branch

Mohammad Kazem Mohammadi ( $\sim$ mkmohamadi@gmail.com )

Islamic Azad University Ahvaz Branch

Ayeh Rayatzadeh

Islamic Azad University Ahvaz Branch

Neda Hasanzadeh

Islamic Azad University Ahvaz Branch

\section{Research Article}

Keywords: Ag2O/GO/TiO2, heterogeneous catalyst, nano composite, Bis (dihydropyrimidinone), tetrahydro-4H-chromenes

Posted Date: December 3rd, 2020

DOI: https://doi.org/10.21203/rs.3.rs-117156/v1

License: (c) (1) This work is licensed under a Creative Commons Attribution 4.0 International License.

Read Full License 


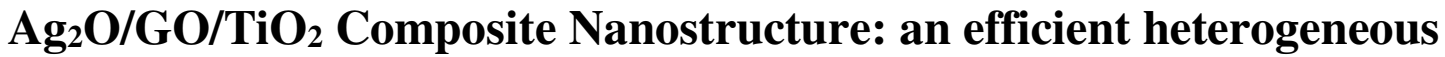

\author{
catalyst for one pot synthesis of
}

\section{Bis (dihydropyrimidinone) and tetrahydro-4H-chromenes derivatives}

\author{
Fatemeh Samandi zadeh, Mohammad Kazem Mohammadi,*Ayeh Rayatzadeh, Neda \\ Hasanzadeh \\ Department of Chemistry, Ahvaz Branch, Islamic Azad University, Ahvaz, Iran. \\ *Corresponding author E-mail:mkmohamadi@gmail.com
}

\begin{abstract}
The simple and efficient synthesis reaction was used for preparing Bis (dihydropyrimidinone) derivatives through Biginelli condensation reaction of terephthalic aldehyde, 1, 3-dicarbonyl compounds and (thio) urea or guanidine and tetrahydro-4H-chromenes via one pot condensation of aromatic aldehydes, malononitrile and dimedone with $\mathrm{Ag}_{2} \mathrm{O} / \mathrm{GO} / \mathrm{TiO}_{2}$ composite nanostructures as a catalyst. The structural functionalities and morphological observations of catalyst were obtained using characterization techniques of field emission scanning electron microscopy (FESEM), X-ray diffraction (XRD), Fourier transfer infrared (FT-IR) spectroscopy and transmission electron microscope (TEM). The structures of Bis (dihydropyrimidinone) and tetrahydro-4H-chromenes confirmed by FT- IR, NMR and mass spectroscopy. Excellent yields of the products, simple reaction process and simple work-up are attractive features of these effective synthesis methods.
\end{abstract}

Keywords: $\mathrm{Ag}_{2} \mathrm{O} / \mathrm{GO} / \mathrm{TiO}_{2}$; heterogeneous catalyst; nano composite; Bis (dihydropyrimidinone); tetrahydro-4H-chromenes

\section{Introduction}


Graphene oxide (GO), consisted of two carbon sheets with closed lattice structure has gathered widespread interest as a catalyst and catalytic support due to presence of surface bound active functional sites, large surface area, and excellent thermal and mechanical properties.[1] Primary cause for high activity of GO is the presence of hydroxyl, carboxylic and epoxy groups, which shows high acidity, excellent oxidizing properties, good conductivity, etc.[2-4] Organic transformations are catalyzed by graphene oxide utilizing its acidic protons or its strong oxidizing ability and has shown potential to replace the traditional metal catalyzed pathways. Numerous one pot syntheses such as a-aminophosphonate synthesis, benzimidazole synthesis, epoxidation, Michael addition, aldol condensation etc., are accelerated by surface bound hydroxyl and carboxylic acid groups in GO.[5-9]

Catalytic activity of graphene oxide refere to presence of functional groups further, the properties of graphene can be amazing by incorporating other functional groups on the GO sheets. Found that synthesis method could impact the properties of graphene oxide [10-12]. Here, we have studied the effect of metal addition to GO on the synthesis of bis (dihydropyrimidon) derivatives. We have chosen multicomponent Biginelli reaction between aryl aldehyde, urea and methyl acetoacetate for synthesis of dihydropyrimidinones as a model reaction.

With the development of nanotechnology, catalysts made of transition metals have drawn a lot of attention due to their application in various areas including organic transformations, rechargeable batteries, and wastewater treatment [13]. Transition metals (Co, $\mathrm{Fe}, \mathrm{Ni}, \mathrm{Mo}, \mathrm{Mn}$, and $\mathrm{Zn}$, etc.) show advantages such as being inexpensive, non-toxic, and abundant in the earth [14]. The applications of $\mathrm{N}^{\wedge} \mathrm{O}$ (ethylimino-methyl) phenol $\mathrm{Fe}(\mathrm{II})$ and Co(II) complexes in ethylene oligomerization catalysis and their structural elucidation were studied by Ngcobo et al. [15]. In artificial photosynthetic systems, hydrogen is generated with molecular catalysts of $\mathrm{Co}, \mathrm{Ni}, \mathrm{Fe}$, and $\mathrm{Mo}[16]$. Du et al. carried out theoretical and experimental studies on metal-organic frame derived ( $\mathrm{M}=\mathrm{Fe}, \mathrm{Ni}, \mathrm{Zn}$, and $\mathrm{Mo}$ ) which were doped into $\mathrm{Co}_{9} \mathrm{~S}_{8}$ nano arrays as an efficient electro catalyst for water splitting [14].

Recently, noticeably growth in the applications of heterogeneous catalysis in organic reactions to carry out synthetic transformations as a consequence of its significance in terms of enviroeconomical and practical aspects [17].

The Biginelli reaction is one of the well-designed methodologies used for the synthesis of dihydropyrimidinone (DHPM) or thione derivatives, an important family of compounds known 
for their diverse pharmacological properties, which can act as antibacterial, antiviral, and calcium channel modulators as well as anticancer and antihypertensive agents. The reported biological activities of DHPMs encourage research groups to produce structurally diverse libraries of bioactive heterocycles [18-21].

This great biological importance of these heterocyclic compounds has prompted the development of new improved methodologies for Biginelli reaction, including transition metal Lewis acid catalysis, [22] solid phase synthesis, [23] ionic liquids, [24] activation with certain additives, [25] microwave-assisted synthesis technique, [26] ultrasound irradiation, [27] solvent-free techniques,[28] grinding techniques,[29] and many new catalysts. [30]

Nevertheless, most protocols have severe limitations, for example, low yields, high cost and catalyst loadings, and low catalyst recovery and recyclability.

Furthermore, questions about the efficacy of solvent-free and/or catalyst-free reactions and the effect of solvent versus solvent free conditions still lead to discussions in the scientific community. To overcome these drawbacks, which have thrown chemists toward the search of new, better, and benign conditions for the biginelli reactions. Transition metal nanoparticles have received a great deal of attention due to a viable alternative to conventional materials in the field of catalyst. Such a new nano catalysts for biginelli reaction are $\mathrm{Nano}-\mathrm{TiCl}_{4} \cdot \mathrm{SiO}_{2}$ [31], $\mathrm{Fe}_{3} \mathrm{O}_{4}$ nanoparticle supported $\mathrm{Ni}$ (II) complexes [32], Niobium Nano catalyst, [33] $\mathrm{Fe}_{3} \mathrm{O}_{4}-$ MWCNT nanocomposite [34], Mesoporous ZnO/AlSBA-15 (7) Nanocomposite [35], Magnetic core-shell Carrageenan $\operatorname{moss} / \mathrm{Fe}_{3} \mathrm{O}_{4}$, [36] Mesoporous silica nano composite, [37] $\mathrm{Fe}_{3} \mathrm{O}_{4} @$ PVA polymeric magnetic nano composite [38] and Magnetic nanoparticles supported imidazolium-based ionic liquids [39].

Also some reaction protocols have applied for the synthesis of tetrahydro-4H-chromenes with the use of nano catalysts such as 4-Dialkylaminopyridine modified magnetic nanoparticles, [40] silica-supported magnetic nanocatalyst, [41]nano- $\mathrm{Fe}_{3} \mathrm{O}_{4},[42] \mathrm{Nano}-\mathrm{SiO}_{2}$, [43]Biopolymerbased Nanomagnetic Catalyst [44] and Nano-coconut Shell-BF 3 [45].

Among these nano catalysts, nano structured compounds based on graghene, such as graphene oxide nanosheet, [46] $\mathrm{BiFeO}_{3}$ nanowire- Reduced Graphene Oxide, [47] clay - graphene oxide nano composite [48], Phosphate functionalized graphene oxide [49] and $\mathrm{Fe}_{3} \mathrm{O}_{4}-\mathrm{GO}-\mathrm{NH}_{2}$ [50] developed for organic synthesis transformations like these two condensation.

A combination of metallic and natural compounds in a single nano composite material has been good idea for catalytic application for several decades. High thermal stability, high acidity, and 
unique nano metric porous network of the zeolites made them the best candidates for introducing an acidic function. There are several catalytic reactions where metal-zeolite composite materials have been efficiently used. [51]

In recent years, several researchers have sought the effect of trimetallic catalysts made of transition metals on catalytic capabilities. However, no studies have been found which survey the synthesis of $\mathrm{Ag}_{2} \mathrm{O} / \mathrm{GO} / \mathrm{TiO}_{2}$ composite nanostructures.

In continuation of our interest in the synthesis of new nanostructure compounds, [52-53] herein, we report the preparation of $\mathrm{Ag}_{2} \mathrm{O} / \mathrm{GO} / \mathrm{TiO}_{2}$ structures on graphene materials and the catalytic activity of this new zeolite nano catalyst was evaluated for the synthesis of a wide range of bis (dihydropyrimidone) benzene and tetrahydro-4H-chromene derivatives with high structural diversity through the reaction protocols. A comparison of the efficiency of this new nano catalyst with that of other known transition metal nano catalysts has revealed interesting and promising results.

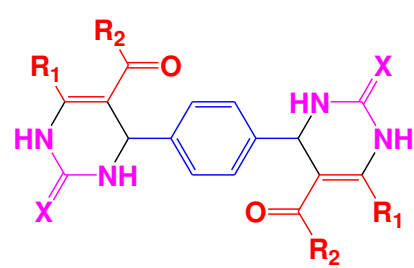

1

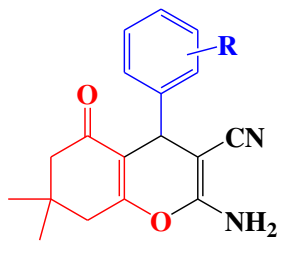

2

Fig 1. Bis (dihydropyrimidinone) (1) and tetrahydro-4H-chromene (2) derivatives

\section{Experimental}

\section{Materials}

Reagents like, silver nitrate $\left(\mathrm{AgNO}_{3}\right)$, sodium hydroxide $(\mathrm{NaOH})$, cetyltrimethylammonium bromide $(\mathrm{CTAB})$ and titanium dioxide $\left(\mathrm{TiO}_{2}\right)$, Ammonium heptamolybdate tetrahydrate $\left(\mathrm{NH}_{4}\right)_{6} \mathrm{Mo}_{7} \mathrm{O}_{24} \cdot 4 \mathrm{H}_{2} \mathrm{O}$, urea (guanidine), 1,4-Benzenedicarboxaldehyde, 1, 3 di carbonyl compounds, malononitrile, dimedone and aromatic aldehydes purchased from Merck company and used without any purifications. Distilled Water is used for these synthesis methods.

\section{Instrumental techniques}


The crystalline phase of the as-synthesized sample was identified by X-ray diffraction (XRD) measurements by the means of a Ultime IV Multipurpose X-ray diffractometer equipped with $\mathrm{Cu} \mathrm{K} \alpha_{1}(\lambda=0.15406 \mathrm{~nm})$ radiation. Fourier transform infrared (FT-IR) spectrum was obtained using a Perkin Elmer BX-II spectrophotometer. Surface morphology was determined from field emission scanning electron microscopy (FESEM, Zeiss SIGMA VP-500) equipped with side detectors including energy-dispersive X-ray spectroscopy (EDS) and high-resolution elemental mapping to examine elemental compositions. The morphological features of the sample were investigated with a Zeiss (EM10C -Germany) transmission electron microscope (TEM) operating at $100 \mathrm{kV}$. All yields refer to isolated products. Products were characterized by comparison of their physical data such as $\mathrm{IR}, 1 \mathrm{H}$ NMR and ${ }_{13} \mathrm{C}$ NMR spectra with authentic samples. By using TMS as internal standard, NMR spectra were recorded in $\mathrm{CDCl}_{3}$ on a Bruker Advance DPX $250 \mathrm{MHz}$ spectrometer. Determination of the products' purity in the course of the reaction were monitored by TLC on silica gel poly gram SILG/UV 254 plates. Mass spectra were recorded on a MS model 5973 Network apparatus at ionization potential of $70 \mathrm{eV}$.

\section{Synthesis of $\mathrm{Ag}_{2} \mathrm{O}$ Nanoparticles}

A wet chemical technique was utilized to synthesize $\operatorname{Ag}_{2} \mathrm{O}$ nanoparticles according to the literature [32]. In a typical synthesis process, $80 \mathrm{~mL}$ of a $0.005 \mathrm{M}$ silver nitrate $\left(\mathrm{AgNO}_{3}\right)$ aqueous solution was heated $60{ }^{\circ} \mathrm{C}$. After that, $20 \mathrm{~mL}$ of a $0.025 \mathrm{M}$ sodium hydroxide aqueous solution was added drop by drop to the prepared $\mathrm{AgNO}_{3}$ solution under continuous magnetic stirring at $60{ }^{\circ} \mathrm{C}$ for $2 \mathrm{~h}$. After cooling to room temperature, the formed precipitate was collected by a centrifuge with a speed of $3000 \mathrm{rpm}$, washed with ethanol several times, and dried at a constant temperature of $40{ }^{\circ} \mathrm{C}$ at $24 h$. 


\section{Synthesis of $\mathrm{Ag}_{2} \mathrm{O} / \mathrm{GO} / \mathrm{TiO}_{2}$ Composite Nanoparticles}

$\mathrm{Ag}_{2} \mathrm{O} / \mathrm{GO} / \mathrm{TiO}_{2}$ composite nanoparticles were synthesized through the sol-gel method according to a process reported by Xiao et al. [54] as follows: Firstly, $5 \mathrm{~g}$ of cetyltrimethylammonium bromide $(\mathrm{CTAB})$ as the precursor of $\mathrm{TiO}_{2}$ was added into $30 \mathrm{~mL}$ of ethanol and kept under continuous stirring. Secondly, $25 \mathrm{~mL}$ of a butyl titanate solution was separately dissolved in 5o $m L$ of absolute ethanol and added into the obtained CTAB solution at a rate of one drop every $3 \mathrm{~s}$. Thirdly, a solution containing $7 \mathrm{mg}$ of as-synthesized $\mathrm{Ag}_{2} \mathrm{O}$ nanoparticles in $5 \mathrm{~mL}$ of absolute ethanol and another solution containing $20 \mathrm{mg}$ of aspurchased graphene oxide in $10 \mathrm{~mL}$ of ethanol were prepared and after $1 \mathrm{~h}$ was slowly added to the above solution. The resultant mixture was stirred for $2 h$ to reach a titanium dioxide gel. The obtained product was finally dried at $65^{\circ} \mathrm{C}$ for $12 \mathrm{~h}$ and calcined at $450^{\circ} \mathrm{C}$ for $2 \mathrm{~h}$.

\section{Typical procedure for the preparation of bis (dihydropyrimidone) derivatives (4a-4g)}

A mixture of the aldehyde ( $2 \mathrm{mmol}), 1,3$ dicarbonyl (2 mmol), urea (3 mmol), ethanol (5 drops) and catalyst $(0.1 \mathrm{mmol})$ was taken in a round bottom flask, heated at $80^{\circ} \mathrm{C}$. The reaction is monitored by Thin Layer Chromatography. After completion, ethanol added and the catalyst was separated by filtration and the solvent was evaporated to obtain the solid product. It is then recrystallized from ethanol. The yield of product was calculated from re-crystallized weight, based on aldehyde. The product was characterized by ${ }^{1} \mathrm{H}$ NMR, ${ }^{13} \mathrm{C}$ NMR, FT-IR and mass spectroscopy. 

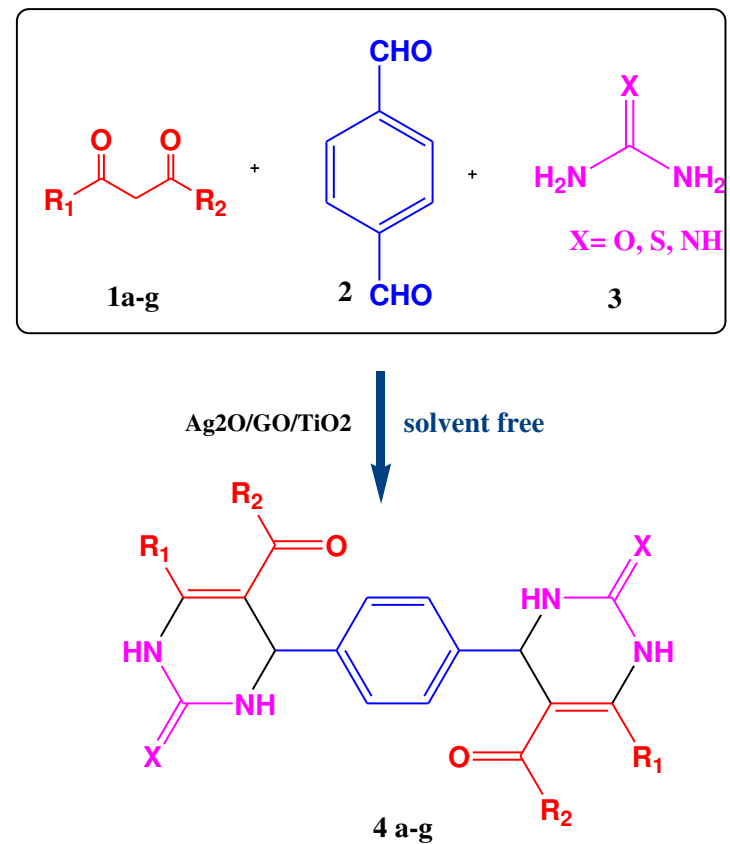

Scheme 1. One pot preparation of bis (dihydropyrimidon) derivatives catalyzed by $\mathrm{Ag}_{2} \mathrm{O} / \mathrm{GO} / \mathrm{TiO}_{2}$

Table 1. One- pot synthesis of compounds (4a-g) with $\mathrm{Ag}_{2} \mathrm{O} / \mathrm{GO} / \mathrm{TiO}_{2}$

\begin{tabular}{|c|c|c|c|c|c|}
\hline Compound & $\mathrm{R}^{1}$ & $\mathrm{R}^{2}$ & $\mathrm{X}$ & Time (min) & Yields (\%) \\
\hline $4 \mathrm{a}$ & $\mathrm{Me}$ & $\mathrm{Me}$ & $\mathrm{O}$ & 30 & 90 \\
\hline $4 \mathrm{~b}$ & $\mathrm{Me}$ & $\mathrm{Me}$ & $\mathrm{S}$ & 25 & 85 \\
\hline $4 \mathrm{c}$ & $\mathrm{Me}$ & $\mathrm{Me}$ & $\mathrm{NH}$ & 35 & 82 \\
\hline $4 \mathrm{~d}$ & $\mathrm{Me}$ & $\mathrm{OEt}$ & $\mathrm{O}$ & 48 & 90 \\
\hline $4 \mathrm{e}$ & $\mathrm{Me}$ & $\mathrm{Ph}$ & $\mathrm{O}$ & 50 & 91 \\
\hline $4 \mathrm{f}$ & $\mathrm{CF}_{3}$ & $\mathrm{Me}$ & $\mathrm{O}$ & 55 & 83 \\
\hline $4 \mathrm{~g}$ & $\mathrm{CF}_{3}$ & 2-thienyl & $\mathrm{O}$ & 40 & 87 \\
\hline
\end{tabular}

\section{Spectral data}

4,4'-(1,4-phenylene)bis(5-acetyl-6-methyl-3,4-dihydropyrimidin-2(1H)-one) 4a:, m.p. 315-

$317{ }^{\circ} \mathrm{C}(\mathrm{dec})$. IR $(\mathrm{KBr}): \lambda_{\max }=3279,3103,2923,1706,1601,1326 \mathrm{~cm}^{-1} .{ }^{1} \mathrm{H}$ NMR (DMSO-

d6) $\square: 9.17$ (sbr, 2H, NH), 7.78 (sbr, 2H, NH), 7.18 (s, 4H, Ar), 5.21 (d, J=3 Hz, 2H, CH), 2.27 
(s, 6H, COMe), 2.10 (s, 6H, Me). ${ }^{13} \mathrm{C}$ NMR (DMSO-d $) \square: 195.0,152.9,148.9,144.3,127.4$, 110.5, 54.3, 31.3, 19.7. MS: (m/z) (\%) $382\left(\mathrm{M}^{+}, 7\right), 354(10), 259(17), 183(100), 155(45)$, 43(95).

1,1'-(4,4'-(1,4-phenylene)bis(6-methyl-2-thioxo-1,2,3,4-tetrahydropyrimidine-5,4-diyl))

diethanone 4b: m.p. $310-312^{\circ} \mathrm{C}(\mathrm{dec})$. IR (KBr): $\lambda_{\max }=3384,3176,2981,1615,1447 \mathrm{~cm}^{-1}$. ${ }^{1} \mathrm{H}$ NMR (DMSO-d $\left.{ }_{6}\right) \square: 10.23$ (s, 2H, NH), 9.66 (s, 2H, NH), 7.17 (s, 4H, Ar), 5.24 (s, 2H, $\mathrm{CH}), 2.29$ (s, 6H, COM), 2.16 (s, 6H, Me). ${ }^{13} \mathrm{C}$ NMR (DMSO-d 6 ) $\square: 193.5,174.6,148.9,144.2$, 127.4, 110.6, 54.5, 31.2, 19.80. MS: (m/z) (\%) $414\left(\mathrm{M}^{+}, 6\right), 325(11), 314(17), 274(19)$, 140(94), 59(100).

\section{1,1'-(4,4'-(1,4-phenylene)bis(2-imino-6-methyl-1,2,3,4-tetrahydropyrimidine-5,4-}

diyl)) diethanone 4c: m.p. $298-300^{\circ} \mathrm{C}(\mathrm{dec}) . \mathrm{IR}(\mathrm{KBr}): \lambda_{\max }=3353,3220,2973,1694,1606$, $1374 \mathrm{~cm}^{-}{ }^{1}{ }^{1} \mathrm{H}$ NMR (DMSO-d $) ~ \square: 9.99$ (sbr, 2H, NH), 7.95 (s 2H, NH), 7.21 (s, 4H, Ar), $6.28(\mathrm{sbr}, 2 \mathrm{H}, \mathrm{NH}), 5.23(\mathrm{~s}, 2 \mathrm{H}, \mathrm{CH}), 2.23$ (s, 6H, COMe), 2.06 (s, 6H, Me). ${ }^{13} \mathrm{C}$ NMR (DMSOd6) $\square: 193.4,178.2,154.3,144.6,127.6,109.5,53.2,31.1,20.1 . \mathrm{MS}:(\mathrm{m} / \mathrm{z})(\%) 380\left(\mathrm{M}^{+}, 9\right)$, 351(11), 307(19), 267(25), 183(78), 59(81), 43(100).

diethyl4,4'-(1,4-phenylene)bis(6-methyl-2-oxo-1,2,3,4-tetrahydropyrimidine-5-

carboxylate) 4d: m.p. $315-317^{\circ} \mathrm{C}(\mathrm{dec}) . \mathrm{IR}(\mathrm{KBr}): \lambda_{\max }=3326,3105,2975,1702,1236 \mathrm{~cm}^{-}$ ${ }^{1} .{ }^{1} \mathrm{H}$ NMR ( DMSO-d $) \square: 9.09$ ( sbr, 2H, NH ), 7.67 (s, 2H, NH ), 7.16 ( s, 4H, Ar), 5.11 (d, J=3.3 Hz, 2H, CH), $3.87\left(\mathrm{q}, \mathrm{J}=7.2 \mathrm{~Hz}, 4 \mathrm{H}, \mathrm{OCH}_{2} \mathrm{CH}_{3}\right), 2.21(\mathrm{~s}, 6 \mathrm{H}, \mathrm{Me}), 1.05$ (t, $\left.\mathrm{J}=7.2 \mathrm{~Hz}, 6 \mathrm{H}, \mathrm{OCH}_{2} \underline{\mathrm{CH}}_{3}\right) .{ }^{13} \mathrm{C}$ NMR (DMSO-d $) \square: 166.2,152.9,149.2,144.7,127.2$, 100.1, 60.1, 51.5, 18.6, 14.9. MS: (m/z) (\%) $442\left(\mathrm{M}^{+}, 7\right), 398(9), 296(21), 256(54)$, 183(73), 59(100).

(4,4'-(1,4-phenylene)bis(6-methyl-2-oxo-1,2,3,4-tetrahydropyrimidine-5,4-diyl))bis 
(phenylmethanone) 4e: m.p. $295-298^{\circ} \mathrm{C}(\mathrm{dec}) . \mathrm{IR}(\mathrm{KBr}): \lambda_{\max }=3312,3110,2923,1702$, $1667 \mathrm{~cm}^{-1} .{ }^{1} \mathrm{H}$ NMR (DMSO-d 6 ) $\square: 9.15$ (s, 2H, NH), 7.75 (sbr, 2H, NH), 7.49-7.38 (m, 10H, $\mathrm{COPh}), 7.13$ (s, 4H, Ar), 5.23 (d, J=2.5 Hz, 2H, CH), 1.64 (s, 6H, Me). ${ }^{13} \mathrm{C}$ NMR (DMSO-d 6 ) $\square: 195.1,152.9,146.5,144.1,141.9,132.3,129.4,128.5,127.2,110.2,55.7,19.3 . \mathrm{MS}:(\mathrm{m} / \mathrm{z})$ (\%) $506\left(\mathrm{M}^{+}, 5\right), 450(7), 410(100), 318(71), 242(85), 126(31), 116(41), 57(26)$.

4,4'-(1,4-phenylene)bis(5-acetyl-6-(trifluoromethyl)-3,4-dihydropyrimidin-2(1H)-one) 4f: m.p. $328-330{ }^{\circ} \mathrm{C}(\mathrm{dec})$. IR (KBr): $\lambda_{\max }=3324,2962,1710,1645,1231 \mathrm{~cm}^{-1} \cdot{ }^{1} \mathrm{H} \mathrm{NMR}$ (DMSO-d $)_{6} \square: 9.48$ (s, 2H, NH), 7.76 (s, 2H, NH), 7.31 (s, 4H, Ar), 5.14 (s, 2H, CH), 2.25 (s, $6 \mathrm{H}, \mathrm{Me}) .{ }^{13} \mathrm{C}$ NMR (DMSO-d 6$) \square: 193.9,152.6,144.4,132.5,129.1,125.9,107.8,50.5,27.6$. MS: (m/z) (\%) $490\left(\mathrm{M}^{+}, 11\right), 256(100), 69(85), 57(81), 43(63)$. 4,4'-(1,4-phenylene)bis(5-(thiophene-2-carbonyl)-6-(trifluoromethyl)-3,4-dihydropyrimidin 2(1H)-one) 4g: m.p. $218-220{ }^{\circ} \mathrm{C}(\mathrm{dec}) . \mathrm{IR}(\mathrm{KBr}): \lambda_{\max }=3157,3089,2912,1658,1603,1205$ $\mathrm{cm}^{-1} .{ }^{1} \mathrm{H}$ NMR (DMSO-d 6 ) $\square: 9.92(\mathrm{~s}, 2 \mathrm{H}, \mathrm{NH}), 7.89(\mathrm{~d}, \mathrm{~J}=4.5 \mathrm{~Hz}, 2 \mathrm{H}$, thienyl), 7.78 (d, J=3.9 $\mathrm{Hz}, 2 \mathrm{H}$, thienyl), 7.69 (s, 2H, NH), 7.50(s, 4H, Ar), 7.16 (dd, J=3.9, 4.5 Hz, 2H, thienyl), 5.61 (s, 2H, CH). ${ }^{13} \mathrm{C}$ NMR (DMSO-d $) \square: 182.3,154.5,146.1,142.4,140.9,138.9,137.0,130.7$, 129.3, 123.2, 104.5, 54.6. MS: (m/z) (\%) $626\left(\mathrm{M}^{+}, 5\right)$, 542(11), 446(15), 397(21), 350(50), 268(71), 222(55), 111(100), 69(91).

\section{Typical procedure for synthesis of tetrahydro-4H-chromenes}

$1 \mathrm{mmol}$ aromatic aldehyde derivatives, $1 \mathrm{mmol}$ malononitrile $(0.066 \mathrm{gr}), 1 \mathrm{mmol}$ dimedone $(0.14 \mathrm{gr})$ and catalyst $(0.2 \mathrm{mmol})$ added to $50 \mathrm{ml}$ round glass balloon equipped with stirrer. This balloon located in the oil bath and refluxed with continues stirring. Reaction progress monitored with ethyl acetat/hexan as an eluent. After the reaction completed, the mixture, 
filtered and dried. The catalyst separated with heating the mixture in the hot ethanol. Product recrystallized in the ethanol and their structures confirmed with the reported article. [55]

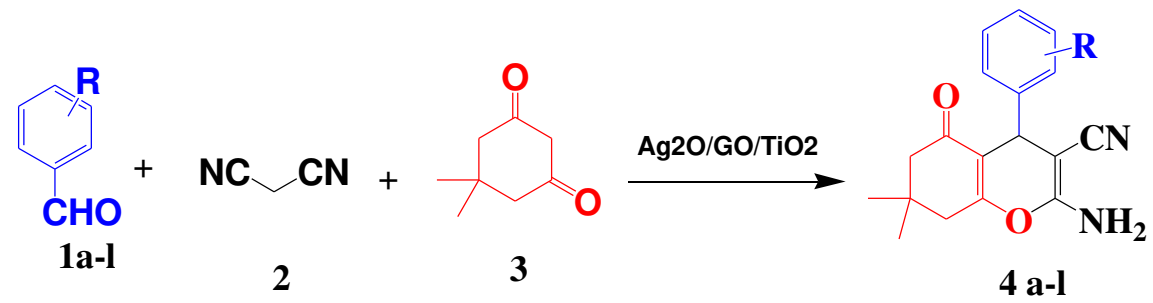

Scheme 2: One pot preparation of tetrahydro- $4 \mathrm{H}$-chromene derivatives catalyzed catalyzed by $\mathrm{Ag}_{2} \mathrm{O} / \mathrm{GO} / \mathrm{TiO}_{2}$

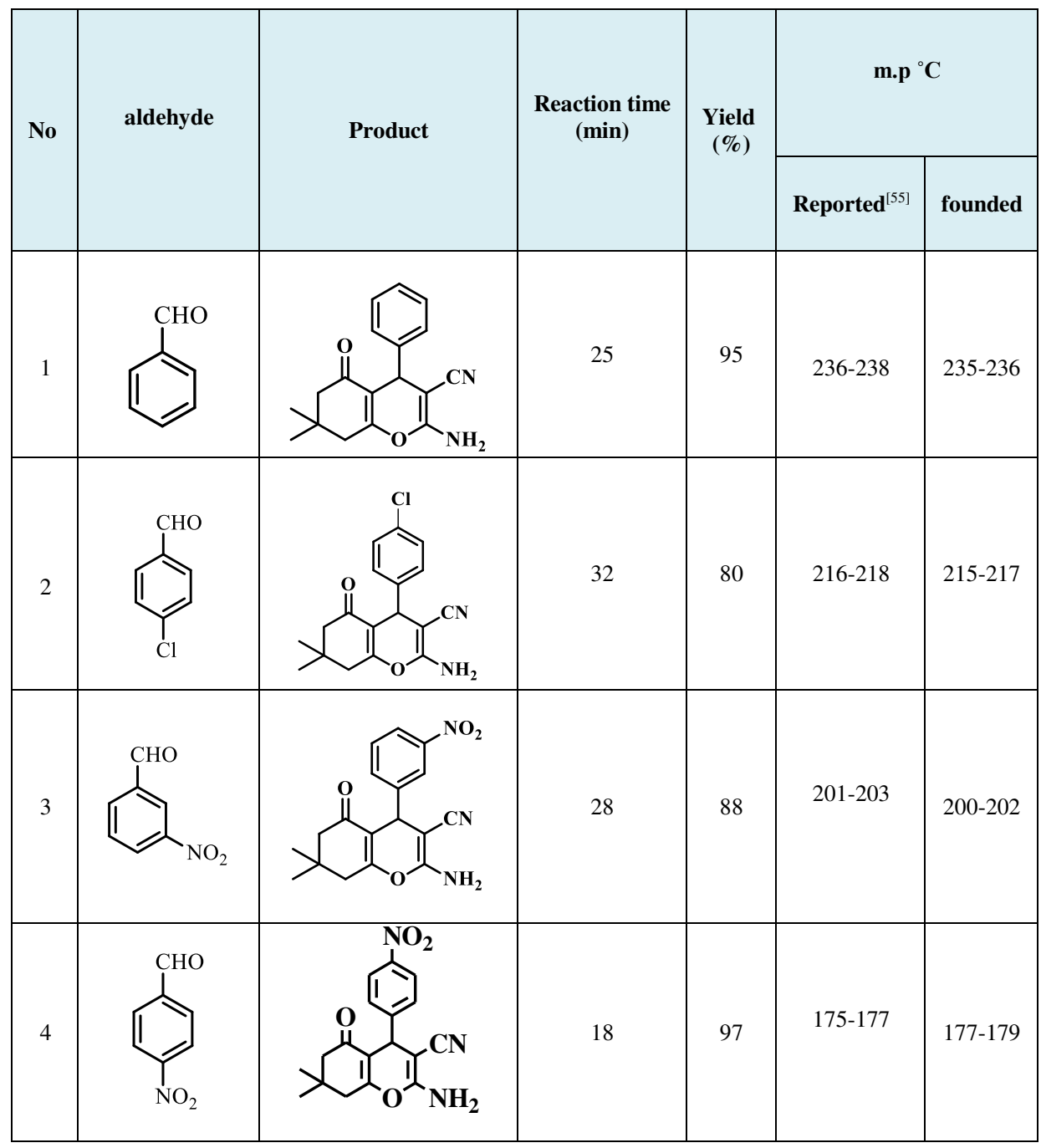




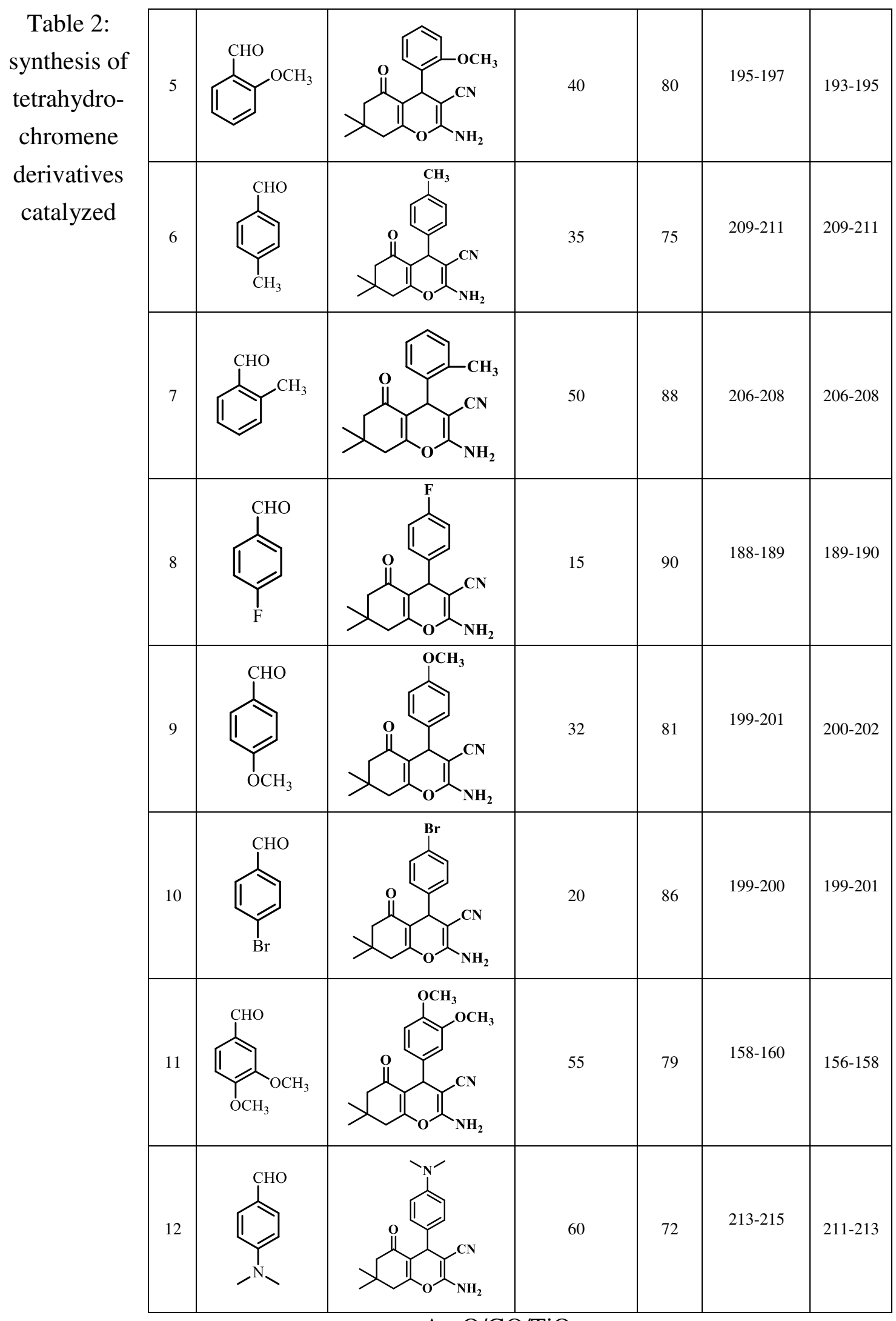

$\mathrm{Ag}_{2} \mathrm{O} / \mathrm{GO} / \mathrm{TiO}_{2}$ 


\section{Results and discussion}

In our attempts to develop a facile one-pot protocols, firstly we focused on the facile condensation of aldehyde ( $2 \mathrm{mmol}), 1,3$ dicarbonyl ester ( $2 \mathrm{mmol})$, urea (thiourea) ( $3 \mathrm{mmol})$ and catalyst $(0.1 \mathrm{mmol})$ at room temperature and in the solvent free condition. This protocol cause to synthesis of bis (dihydropyrimidon) benzene derivatives in good yields and short reaction times.

Table 1 summarizes the results for reactions of terephthalic aldehyde with various derivatives of $\mathbf{1}$ and 2. We initially examined the reaction of acetylacetone (1a) with urea (2a) and terephthalic aldehyde (3) in the presence of $\mathrm{Ag}_{2} \mathrm{O} / \mathrm{GO} / \mathrm{TiO}_{2}$ under microwave irradiation conditions at $100{ }^{\circ} \mathrm{C}$ (Scheme 1). Experiments showed that small amount of catalyst are enough for the reaction to complete in short reaction times (as indicated by TLC). Alternatively, we didn't see any products in the absence of catalyst. The structure of product $\mathbf{4 e}$ in was elucidated 
by spectroscopy methods and its purity was confirmed by elemental analysis. The optimized conditions utilize a 1: 1: 1.5: 0.1 ratio of di aldehyde, 1,3-dicarbonyl compounds, thiourea and nano catalyst (Table 1). The procedure is shown to be equally efficient when thiourea is replaced with urea or guanidine. In addition, it can be concluded from both ${ }^{1} \mathrm{H} N \mathrm{NR}$ and ${ }^{13} \mathrm{C}$ NMR spectra of the product that the reaction is stereospecific loading to exclusive formation of one the meso or dl diastereoproducts from which the meso product is shown here for the simplicity.

However, other protocols for synthesis of tetrahydro-4H-chromene derivatives via the pone pot condensation of $1 \mathrm{mmol}$ aromatic aldehydes, $1 \mathrm{mmol}$ malononitrile $(0.066 \mathrm{gr})$ and $1 \mathrm{mmol}$ dimedon $(0.14 \mathrm{gr})$ in the presence of nano catalyst $(0.2 \mathrm{mmol})$ at reflux condition.

Further, the product formed with the addition of distilled water with continues mixing of reaction mixture at room temperature in $20 \mathrm{~min}$. After the completion of reaction, the residue was taken into ethanol and filtered. The crude product is obtained by evaporating the filtrate. Recrystallization of the crude product led to the isolation of crystalline solid products in short reaction time and high product yield.

With this successful and efficient three-component reaction, synthesis of diverse tetrahydro4H-chromene derivatives was undertaken. The aromatic aldehydes consist of electronwithdrawing and electron donating groups were found to be equally effective to produce the products in good yields (Table 2). It seems that the role of $\mathrm{Ag}_{2} \mathrm{O} / \mathrm{GO} / \mathrm{TiO}_{2}$ nano composite in this protocol is the help to formation of carbanion form malononitrile and dimedone to reaction with aromatic aldehyde derivatives.

Phase compositions of as-synthesized nanoparticles were identified using the X-ray diffraction (XRD) technique. Fig. 2 displays the XRD pattern of $\mathrm{Ag}_{2} \mathrm{O} / \mathrm{GO} / \mathrm{TiO}_{2}$ composite nanoparticles. The XRD pattern of the composite nanoparticles exhibits four distinct peaks at $25.76^{\circ}, 48.49^{\circ}, 54.39^{\circ}$ and $55.53^{\circ}$ corresponding to (101), (200), (105), and (211) crystal planes of anatase $\mathrm{TiO}_{2}$ crystalline structure, respectively (JCPDS No. 00-021-1272). Two diffraction peaks are also found at $62.98^{\circ}$ and $69.29^{\circ}$, which can be assigned to (214) and (301) planes of the $\mathrm{TiO}_{2}$ rutile phase, respectively, (JCPDS card No. 00-021-1276). The formation of $\mathrm{Ag}_{2} \mathrm{O}$ structures is confirmed by arising characteristic peaks at $38.30^{\circ}, 70.76^{\circ}$, and $75.55^{\circ}$ relevant to 
(200), (222), and (311) Bragg planes, respectively (JCPDS No. 01-072-2108). As shown in Fig, 2, the presence of graphene sheets is justified by appearing a characteristic peak at $13.45^{\circ}$ that can be indexed to carbon structures as presented in JCPDS card No. 01-089-8491. It is well known that the existence of GO in semiconductor composite structures compared to other carbon materials can improve the transitional performance of charge carriers relevant to hightemperature thermal effects.

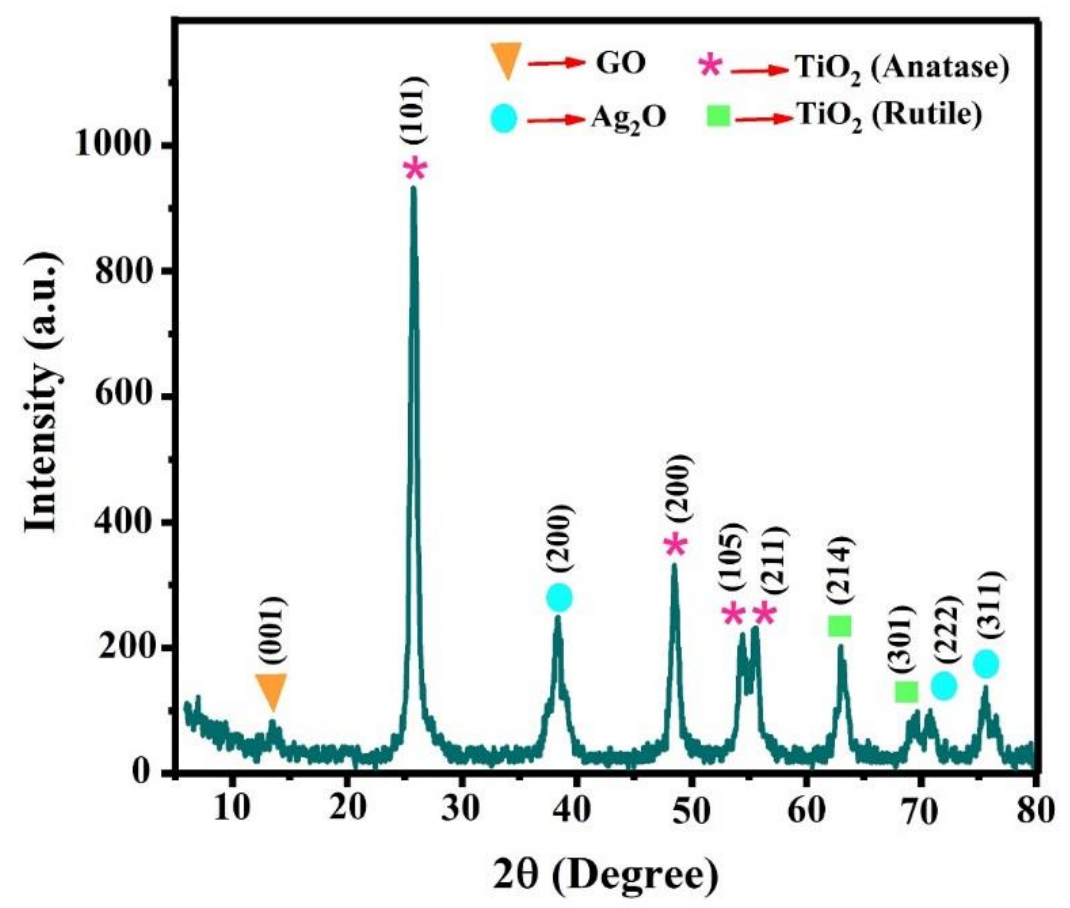

Fig. 2. $\mathrm{XRD}$ pattern of $\mathrm{Ag}_{2} \mathrm{O} / \mathrm{GO} / \mathrm{TiO}_{2}$ composite nanoparticles.

The surface chemical composition of the as-synthesized sample was investigated by FT-IR spectroscopy. Fig. 3 shows the FT-IR pattern of $\mathrm{Ag}_{2} \mathrm{O} / \mathrm{GO} / \mathrm{TiO}_{2}$ composite nanoparticles in the range of $450-4000 \mathrm{~cm}^{-1}$. It can be seen in Fig. 2 that, due to Ti-O stretching in $\mathrm{TiO}_{2}$ lattice, the absorption band appears at $716.64 \mathrm{~cm}^{-1}$. The characteristic band at $2331.95 \mathrm{~cm}^{-1}$ is ascribed to the stretching modes of carboxyl $(\mathrm{C}=\mathrm{O})$ groups. The band observed at $2828.11 \mathrm{~cm}^{-1}$ also corresponds to the $\mathrm{C}-\mathrm{H}$ stretching frequency. 


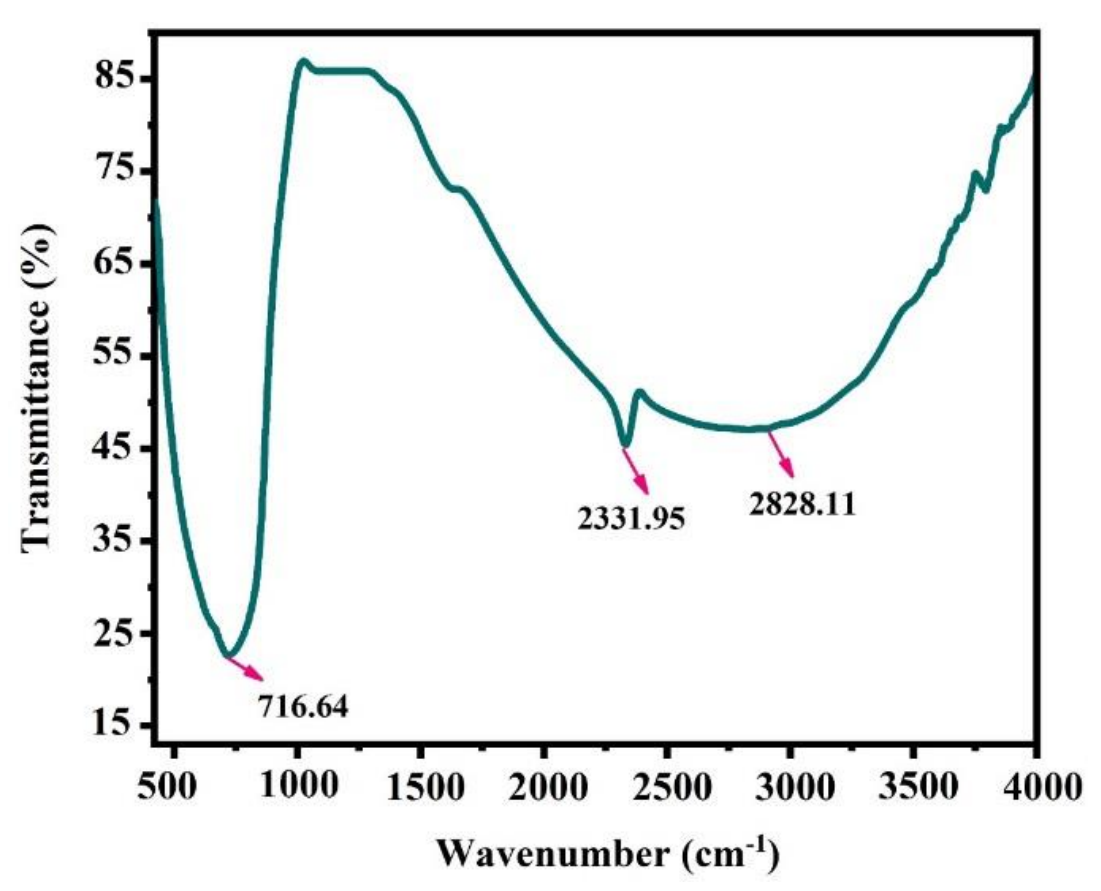

Fig. 3. FTIR pattern of $\mathrm{Ag}_{2} \mathrm{O} / \mathrm{GO} / \mathrm{TiO}_{2}$ composite nanoparticles.

The surface morphology of the as-synthesized sample was observed using FESEM micrographs. FESEM images of $\mathrm{Ag}_{2} \mathrm{O} / \mathrm{GO} / \mathrm{TiO}_{2}$ composite nanoparticles in two different magnifications along with the corresponding histograms of particle size have been illustrated in Fig. 4. The FESEM image shown in Fig. 3a indicates a relatively uniform distribution from spherical-like particles with an average diameter of about $300 \mathrm{~nm}$ (Fig. 4c). It can be seen in Fig. $3 \mathrm{~b}$ that the obtained spherical structures consist of numerous small nanoparticles with an average size of about $35 \mathrm{~nm}$ (Fig. 4d). Such a formed architecture revealed more available surface areas compared to that with simple spherical structures resulting in more improved performances for potential applications such as synthesis catalyst. 

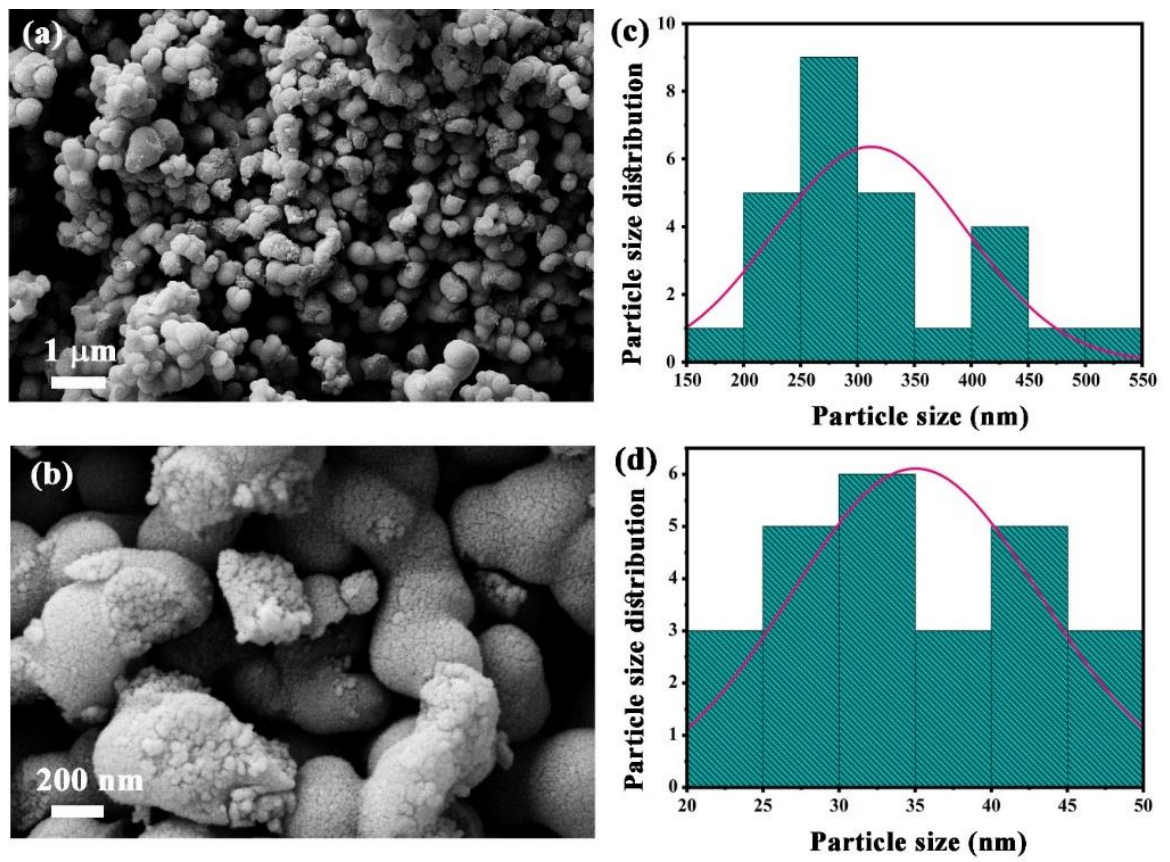

Fig. 4. (a, b) Typical FESEM images and (c, d) the corresponding histograms of particle size for $\mathrm{Ag}_{2} \mathrm{O} / \mathrm{GO} / \mathrm{TiO}_{2}$ composite nanoparticles.

FESEM-EDS mapping was carried out to verify the surface element dispersion states of the as-synthesized sample. Fig. 5 presents the results obtained from the FESEM-EDS mapping of $\mathrm{Ag}_{2} \mathrm{O} / \mathrm{GO} / \mathrm{TiO}_{2}$ composite nanoparticles. Fig. 5b-e demonstrates the presence and uniform distribution of $\mathrm{Ti}, \mathrm{O}, \mathrm{C}$, and $\mathrm{Ag}$ elements in the selected surface area of the as-synthesized sample (Fig. 5a), offering visual evidence for the successful formation of $\mathrm{Ag}_{2} \mathrm{O} / \mathrm{GO} / \mathrm{TiO}_{2}$ composite nanoparticles. EDS spectrum recorded for $\mathrm{Ag}_{2} \mathrm{O} / \mathrm{GO} / \mathrm{TiO}_{2}$ sample is also plotted as an inset in Fig. 5a indicating the existence of Ti, O, C, and Ag with atom percentages of 50.3\%, $23.1 \%, 6.3 \%$, and $20.3 \%$ in $\mathrm{Ag}_{2} \mathrm{O} / \mathrm{GO} / \mathrm{TiO}_{2}$ composite structure, respectively. 

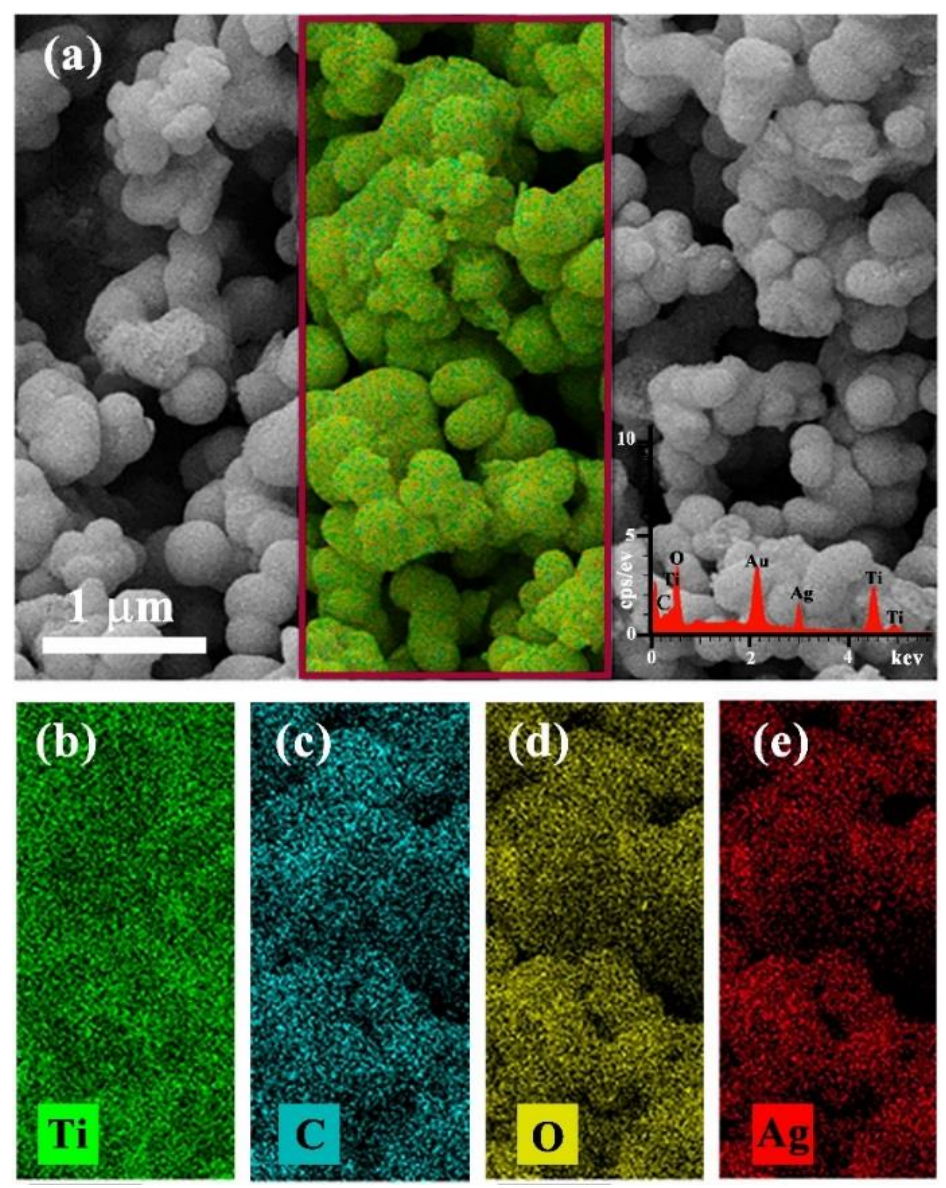

Fig. 5. (a) FESEM image; Inset: corresponding EDS spectrum, and (b-e) EDS mappings of $\mathrm{Ag}_{2} \mathrm{O} / \mathrm{GO} / \mathrm{TiO}_{2}$ composite nanoparticles.

The morphological features of the sample were investigated with a Zeiss (EM10C -Germany) transmission electron microscope (TEM) operating at $100 \mathrm{kV}$. These images were prepared as follows: The dilute aqueous solution of the sample was sonicated for $15 \mathrm{~min}$. Then, a portion of the sample $(20 \mu \mathrm{L})$ was dropped onto holey carbon film on copper grid 300 mesh (EMSUSA) and dried thoroughly at room temperature.

For the closer look of synthesized microstructures, used of the transmission electron microscope (TEM). Transmission electron microscope image of $\mathrm{Ag}_{2} \mathrm{O} / \mathrm{GO} / \mathrm{TiO}_{2}$ showed in Fig. 6. TEM image of $\mathrm{Ag}_{2} \mathrm{O} / \mathrm{GO} / \mathrm{TiO}_{2}$ to be observed with the $50 \mathrm{~nm}$ to $300 \mathrm{~nm}$ magnification. According to figures, it can be said that the particles have Irregular geometric shapes. 


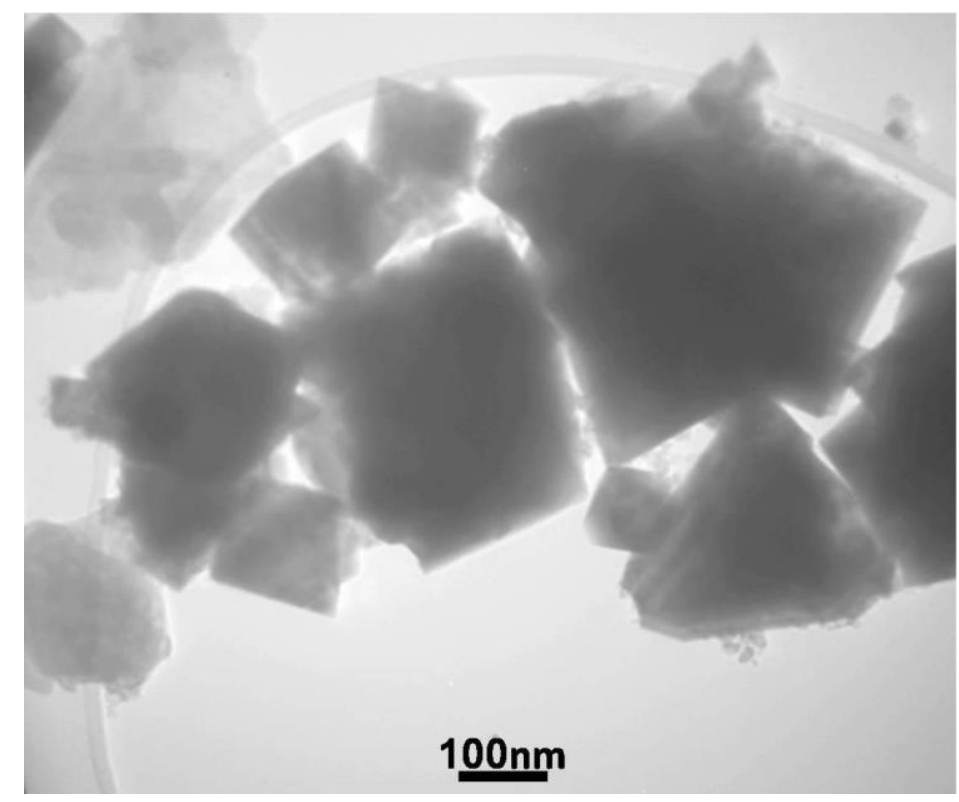

Fig.6. TEM image of $\mathrm{Ag}_{2} \mathrm{O} / \mathrm{GO} / \mathrm{TiO}_{2}$ composite nanoparticles.

\section{Conclusions}

$\mathrm{Ag}_{2} \mathrm{O} / \mathrm{GO} / \mathrm{TiO}_{2}$ composite nanoparticles were successfully synthesized via a two-step process. The formation and composition of composite structures were investigated by the XRD, FT-IR, and FESEM methods. The structural studies demonstrated the fabrication of spherical structures with an average diameter of about $300 \mathrm{~nm}$ composed of nanoparticles with an average size of about $35 \mathrm{~nm}$. The optical studies were also performed by UV-Vis diffuse reflectance spectroscopy and indicated an absorption edge in the UV region with band-gap energy of about $3.2 \mathrm{eV}$. In conclusion, we founded the versatile and simple method for the synthesis of new $\mathrm{Ag}_{2} \mathrm{O} / \mathrm{GO} / \mathrm{TiO}_{2}$ composite nanoparticles with the doped nanostructured $\mathrm{Ag}_{2} \mathrm{O}$ and $\mathrm{TiO}_{2}$ on the graphene surface that could the best candidate for synthesis of bis (dihydropyrimidone) and tetrahydro-4H-chromene derivatives.

This method not only preserved the simplicity one-pot condensation, but also remarkably improved the yields $(>80 \%)$ of products in shorter reaction times as against the longer reaction times required for other catalysts after the addition of a low catalyst concentration. The 
procedure gives the products in good yields and avoids problems associated with solvent use (cost, handling, safety and pollution), and easy experimental work-up procedure, hence, it is a useful addition to the existing methods.

\section{Acknowledgment}

The current study was partially supported by the Islamic Azad University Ahvaz Branch. The authors would like to thank the Research Council for their generous support of this work.

\section{Reference}

[1] B. Garg, Y.-C. Ling, Green Mater. Versatilities of graphene-based catalysts in organic transformations. 2013, 1, 47-61.

[2] J. T. Robinson, F. K. Perkins, E. S. Snow, Z. Wei, P. E. Sheehan, Reduced Graphene Oxide Molecular Sensors. Nano Lett. 2008, 8, 3137-3140.

[3] H. Wang, Q. Hao, X. Yang, L. Lu, X. Wang, Graphene Oxide Doped Polyaniline for Supercapacitors Electrochem. Commun. 2009, 11, 1158-1161.

[4] L. L. Zhang, X. Zhao, M. D. Stoller, Y. Zhu, H. Ji, S. Murali, Y. Wu, S. Perales,

B. Clevenger, R. S. Ruoff, Highly conductive and porous activated reduced graphene oxide films for high-power supercapacitors. Nano Lett. 2012, 12, 1806-1812.

[5] A. Dhakshinamoorthy, M. Alvaro, P. Concepcijn, V. Forn8s, H. Garcia, Graphene oxide as an acid catalyst for the room temperature ring opening of epoxides Chem. Commun. 2012, 48, 5443-5445.

[6] K. B. Dhopte, D. S. Raut, A. V. Patwardhan, P. R. Nemade, Graphene Oxide as Recyclable Catalyst for One-Pot Synthesis of $\alpha$-Aminophosphonates Synth. Commun. 2015, 45, 778-788. [7] K. B. Dhopte, R. S. Zambare, A. V. Patwardhan, P. R. Nemade, Role of graphene oxide as a heterogeneous acid catalyst and benign oxidant for synthesis of benzimidazoles and benzothiazoles RSC Adv. 2016, 6, 8164-8172.

[8] S. M. Islam, A. S. Roy, R. C. Dey, S. Paul, Graphene based material as a base catalyst for solvent free Aldol condensation and Knoevenagel reaction at room temperature J. Mol. Catal. Chem. 2014, 394, 66-73.

[9] S. Verma, H. P. Mungse, N. Kumar, S. Choudhary, S. L. Jain, B. Sain, O. P.

Khatri, Graphene oxide: an efficient and reusable carbocatalyst for aza-Michael addition of amines to activated alkenes. Chem. Commun. 2011, 47, 12673-12675.

[10] M. M. Kadam, O. R. Lokare, K. V. M. K. Kireeti, V. G. Gaikar, N. Jha, Impact of the degree of functionalization of graphene oxide on the electrochemical charge storage property and metal ion adsorption. RSC Adv. 2014, 4, 62737-62745.

[11] K. Krishnamoorthy, M. Veerapandian, K. Yun, S.-J. Kim, The chemical and structural analysis of graphene oxide with different degrees of oxidation Carbon 2013, 53, 38-49.

[12] H. Yan, X. Tao, Z. Yang, K. Li, H. Yang, A. Li, R. Cheng, Effects of the oxidation degree of graphene oxide on the adsorption of methylene blue. J. Hazard. Mater. 2014, 268, 191-198. 
[13] Allaedini, G., Tasirin, S.M., Aminayi, P.: Synthesis of Fe-Ni-Ce trimetallic catalyst nanoparticles via impregnation and co-precipitation and their application to dye degradation. Chem. Pap. 70, 231-242 (2016).

[14] Du, X., Su, H., Zhang, X.: Metal-organic framework-derived M (M = Fe, Ni, Zn, and Mo) doped Co9S8 nanoarrays as efficient electrocatalyst for water splitting: The combination of theoretical calculation and experiment J. Catal. 383, 103-116 (2020).

[15] Ngcobo, M., Nyamato, G.S., Ojwach, S.O.: Structural elucidation of $\mathrm{N}^{\wedge} \mathrm{O}$ (ethyliminomethyl)phenol $\mathrm{Fe}$ (II) and $\mathrm{Co}$ (II) complexes and their applications in ethylene oligomerization catalysis. Mol. Catal. 478. 110590 (2019).

[16] Eckenhoff, W.T.: Molecular catalysts of $\mathrm{Co}, \mathrm{Ni}, \mathrm{Fe}$, and Mo for hydrogen generation in artificial photosynthetic systems. Coord. Chem. Rev. 373, 295-316 (2018).

[17] Adrienn, H., Zolta'n, H., Ilona, V.: Convenient one-pot heterogeneous catalytic method for the preparation of 3,4- Dihydropyrimidin-2(1H)-ones. Synth. Commun. 36(1), 129-136 (2006)

[18] P. Sanjeev and G.S. Gokavi,Heteropoly acid catalyzed synthesis of 3, 4-dihydropyrimidin2 (1H)-ones .Catal. Commun., 2007, 8, 279-284.

[19] (a) D. Nagarathnam, S.W. Miao, B. Lagu, M.C. Harrell, K.P. Vyas and

C. Gluchowski, J. Med. Chem., 1999, 42, 4764-4777. (b) J.C. Barrow, P.G. Nantermet, D. Nagarathnam and C. Forray, J. Med. Chem., 2000, 43, 2703-2718.

[20] C.O. Kappe, 100 Years of the Biginelli Dihydropyrimidine Synthesis. Tetrahedron, 1993, 49, 6937-6963.

[21] G.I. Grover, S. Dzwonczyk, D.M. McMullen, D.E. Normadin, C.S. Parham, P.G. Sleph and S.J. Moreland, J. Cardiovasc. Pharmacol., 1995, 26, 289-291.

[22] (a) D. S. Bose, L. Fatima, H. B. Mereyala, J Org Chem., 2003, 68, 587; (b) M. Adib, K. Ghanbary, M. Mostofi, M. R. Ganjal, Molecules., 2006, 11, 649; (c) M. A. Chari, K. Syamasundar, J Mol Catal A., 2004, 221, 137.

[23] D. Dallinger, N. Yu Gorobets, C. O. Kappe, High-Throughput Synthesis of N3-Acylated Dihydropyrimidines Combining Microwave-Assisted Synthesis and Scavenging Techniques. Org Lett. 2003, 5, 1205.

[24] (a) E. H. Hu, D. R. Sidler, U. H. Dolling, J Org Chem., 1998, 63, 3454; (b) A. Dondoni, A. Massi, Tetrahedron Lett., 2001, 42, 7975; (c) J. Peng, Y. Deng, Tetrahedron Lett., 2001, 42, 5917.

[25] (a) J. S. Yadav, B. V. Subba Reddy, K. Bhaskar Reddy, K. S. Raj, A. R. Prasad, J Chem Soc Perkin Trans., 2001, 1, 1939; (b) I. Saxena, D. C. Borah, J. C. Sarma, Tetrahedron Lett., 2005, 46, 1159; (c) J. C. Bussolari, P. A. McDonnell, J Org Chem., 2000, 65, 6777.

[26] (a) C. O. Kappe, D. Kumar, R. S. Varma, Synthesis., 1999, 1799; (b) E. H. Hu, D. R. Sidler, U. H. Dolling, J Org Chem., 1998, 63, 3454.

[27] (a) J. T. Li, J.F. Han, J. H. Yang, T. S. Li, Ultrason Sonochem., 2003, 10, 119; (b) H. R. Memarian, M. Soleymani, Ultrason Sonochem., 2011, 18, 745.

[28] D. Alessandro, M. Alessandro, Parallel synthesis of dihydropyrimidinones using Yb(III)resin and polymer-supported scavengers under solvent-free conditions. A green chemistry approach to the Biginelli reaction. Tetrahedron Lett., 2001, 42, 7975.

[29] B. C. Ranu, A. Hajra, S. S. Dey, A Practical and Green Approach towards Synthesis of Dihydropyrimidinones without Any Solvent or Catalyst. Org. Proc. Res. Dev. 2002, 6, 6, 817 818

[30] F. Xu, D. Huang X. Lin, Y. Wang, Highly enantioselective Biginelli reaction catalyzed by SPINOL-phosphoric acids. Org. Biomol. Chem., 2012, 10, 4467 
[31] Bi Bi Fatemeh Mirjalili* and Leila Zamani, Nano-Ticl4.SiO2: a Versatile and Efficient Catalyst for Synthesis of Dihydropyrimidones via Biginelli Condensation. S. Afr. J. Chem., 2014, 67, 21-26,

[32] D. Girija , H.S. Bhojya Naik , B. Vinay Kumar , C.N. Sudhamani , K.N. Harish. Fe3O4 nanoparticle supported Ni (II) complexes: A magnetically recoverable catalyst for Biginelli reaction. Arabian Journal of Chemistry (2019) 12, 420-428

[33] Carolina G. S. Lima, Sandrina Silva, Ricardo H. GonAalves, Edson R. Leite, Ricardo S. Schwab, Arlene G. CorrTa, and M_rcio W. Paix.o. Highly Efficient and Magnetically Recoverable Niobium Nanocatalyst for the Multicomponent Biginelli Reaction. ChemCatChem 2014, 6, 3455 - 3463

[34] Javad Safari,* Zohre Zarnegar. Biginelli reaction on Fe3O4-MWCNT nanocomposite: excellent reactivity and facile recyclability of the catalyst combined with ultrasound irradiation. RSC Adv., 2013, 3, 17962-17967.

[35] Mesoporous ZnO/AlSBA-15 (7) Nanocomposite as An Efficient Catalyst for Synthesis of 3,4-dihydropyrimidin-2(1H)-one via Biginelli Reaction and Their Biological Activity Study Birendra Nath Mahato*, T. Krithiga , Bulletin of Chemical Reaction Engineering \& Catalysis, 14 (3) 2019, 634-645.

[36] Hossein Mohammad Zaheri, Shahrzad Javanshir , Behnaz Hemmati, Zahra Dolatkhah and Maryam Fardpour. Magnetic core-shell Carrageenan moss/Fe3O4: a polysaccharidebased metallic nanoparticles for synthesis of pyrimidinone derivatives via Biginelli reaction. Chemistry Central Journal (2018) 12:108 .

[37] A. Bashti and A.R. Kiasat . Biginelli Multicomponent Condensation Reaction Promoted by 4,4'-Bipyridinium Dichloride Ordered Mesoporous Silica Nanocomposite under Solvent Free Conditions. Org. Chem. Res., Vol. 2, No. 1, 28-38, March 2016.

[38] Ali Maleki , Maryam Niksefat, Jamal Rahimi and Zoleikha Hajizadeh . Design and preparation of Fe3O4@PVA polymeric magnetic nanocomposite

film and surface coating by sulfonic acid via in situ methods and evaluation of its catalytic performance in the synthesis of dihydropyrimidines . BMC Chemistry (2019) 13:19

[39] Zohre Zarnegar - Javad Safari. Magnetic nanoparticles supported imidazolium-based ionic liquids as nanocatalyst in microwave-mediated solvent-free Biginelli reaction. J Nanopart Res (2014) 16:2509.

[40] . Virgilio D. Ebajo Jr, Cybele Riesse L. Santos, Glenn V. Alea2*, Yuya A. Lin

$\&$ Chun-Hu Chen . Regenerable Acidity of Graphene Oxide in Promoting Multicomponent Organic Synthesis. Scientific Reports (Nature Publisher Group); London Vol. 9, (Oct 2019): $1-12$

[40]Soheila khajeh Dangolani,a Farhad Panahi,, Maryam Nourisefat, and Ali Khalafi-Nezhad . 4-Dialkylaminopyridine modified magnetic nanoparticles: as an efficient nano-organocatalyst for one-pot synthesis of 2-amino-4H-chromene-3-carbonitrile derivatives in water. RSC advances. Issue 95, 2016, Issue in Progress

[41]Ali maleki, sepide azadegan. Preparation and characterization of silica-supported magnetic nanocatalyst and application in the synthesis of 2-amino-4H-chromene-3-carbonitrile derivatives. Inorganic and nano metal chemistery. Volume 47, 2017 - Issue 6.

[42]Bagher Amirheidari, Mohammad Seifi, Mehdi Abaszadeh. Evaluation of magnetically recyclable nano-Fe3O4 as a green catalyst for the synthesis of mono- and bistetrahydro-4Hchromene and mono and bis1,4-dihydropyridine derivatives. Res Chem Intermed (2016) 42:3413-3423. 
[43]Ebrahim Mollashahi *, Mohammad Nikraftar. Nano-SiO2 catalyzed three-component preparations of pyrano[2,3-d]pyrimidines, 4H-chromenes, and dihydropyrano[3,2c]chromenes. Journal of Saudi Chemical Society (2018) 22, 42-48.

[44]Amin Mohammadzadeh, Ahmad Poursattar Marjani and Asghar Zamani. . A Novel Biopolymer-based Nanomagnetic Catalyst for the Synthesis of 4H-pyran and Tetrahydro-4Hchromene Derivatives. S. Afr. J. Chem., 2020, 73, 55-63,

[45] Hamid Reza Molaei, Bahareh Sadeghi. Microwave Assisted Multi-component Synthesis of 4H-chromene Derivatives by Nano-coconut Shell-BF3 as a New Heterogeneous Catalyst.

Journal of Applied Chemical Research, 13, 1, 85-96 (2019).

[46] Esmail Vessally, Akbar Hassanpour, Rahim Hosseinzadeh-Khanmiri, Mirzaagha Babazadeh, - Jafar Abolhasani . Green and recyclable sulfonated graphene and graphene oxide nanosheet catalysts for the syntheses of 3,4-dihydropyrimidinones. Monatshefte für Chemie Chemical Monthly volume 148, pages321-326(2017)

[47] Debabrata Moitra, Barun Kumar Ghosh, Madhurya Chandel and Narendra Nath Ghosh. Synthesis of a $\mathrm{BiFeO} 3$ nanowire-reduced graphene oxide based magnetically separable nanocatalyst and its versatile catalytic activity towards multiple organic reactions. RSC advances. 100, 2016, Page 97464 to 98553

[48] Divya P. Narayanan , Anila Gopalakrishnan, Zahira Yaakob , Sankaran Sugunan , Binitha N. Narayanan . A facile synthesis of clay - graphene oxide nanocomposite catalysts for solvent free multicomponent Biginelli reaction .Arabian Journal of Chemistry (2020) 13, 318-334

[49] L. Satish K. Achary, Aniket Kumar, Lipeeka Routa, Swaroop V.S. Kunapuli, Rajendra S. Dhakab, Priyabrat Dash. Phosphate functionalized graphene oxide with enhanced catalytic activity for Biginelli type reaction under microwave condition. Chemical Engineering Journal 331 (2018) 300-310

[50] Shahnaz Rostamizadeh, Asieh Hemmasi 1, Negar Zekri. Magnetic amine-functionalized graphene oxide as a novel and recyclable bifunctional nanocatalyst for solvent-free synthesis of pyrano[3,2-c]pyridine derivatives. Nanochem Res 2(1): 29-41, Winter and Spring 2017

[51] Nyankson, E., Adjasoo, Jonas. Kwame Efavi, J., Yaya, Abu. Manu, G., Kingsford, A., Yeboah Abrokwah, R.: Synthesis and kinetic adsorption characteristics of Zeolite/CeO2 nanocomposite Scient. Afr. 7, e00257 (2020).

[52] Mohammadi, M.K., Gutiérrez, A., Hayati, P., Mohammadi, K., Rezaei, R.: Diverse structural assemblies and influence in the morphology of different parameters in a series of OD and 1D mercury(II) metal-organic coordination complexes by the sonochemical process. Polyhedron. 160, 20-34 (2019)

[53] Mohammad Kazem Mohammadi. Solvent-free synthesis of oxovanadium (V) complexes with isatin base schiff ligands. Inorganic and Nano-Metal Chemistry. 2017, VOL. 47, NO. 9, $1323-1327$

[54] L. Xiao, L. Youji, C. Feitai, X. Peng, L. Ming, Facile synthesis of mesoporous titanium dioxide doped by Ag-coated graphene with enhanced visible-light photocatalytic performance for methylene blue degradation, RSC Adv. 7 (2017) 25314-25324.

[55] Dalip Kumar, V. Buchi Reddy, Shashwat Sharad, Urvashi Dube, Suman Kapur . A facile one-pot green synthesis and antibacterial activity of 2-amino-4H-pyrans and 2-amino-5oxo-5,6,7,8- tetrahydro-4H-chromenes. European Journal of Medicinal Chemistry. 44 (2009) $3805-3809$ 
Figures

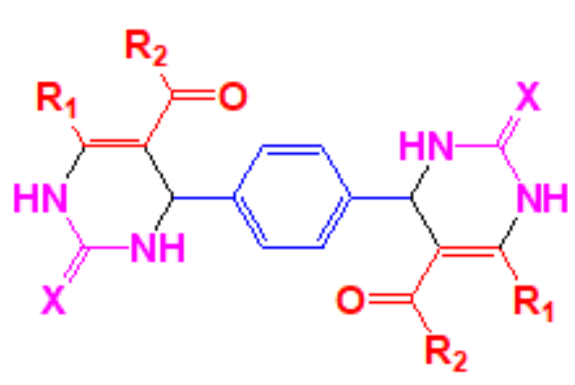

1<smiles>[R]C1=CC=CCC1C1C(C#N)=C(N)OC2=C1C(=O)CC(C)(C)C2</smiles>

2

\section{Figure 1}

Bis (dihydropyrimidinone) (1) and tetrahydro-4H-chromene (2) derivatives<smiles>[R]C(=O)C1=C([R])NC([X])=NC1c1ccc(C2NC([X])NC([R])C2C([R])=O)cc1</smiles>

1<smiles>[R][X]1cccc(C2C(C#N)=C(N)OC3=C2C(=O)CC(C)(C)C3)c1</smiles>

2

\section{Figure 1}

Bis (dihydropyrimidinone) (1) and tetrahydro-4H-chromene (2) derivatives 


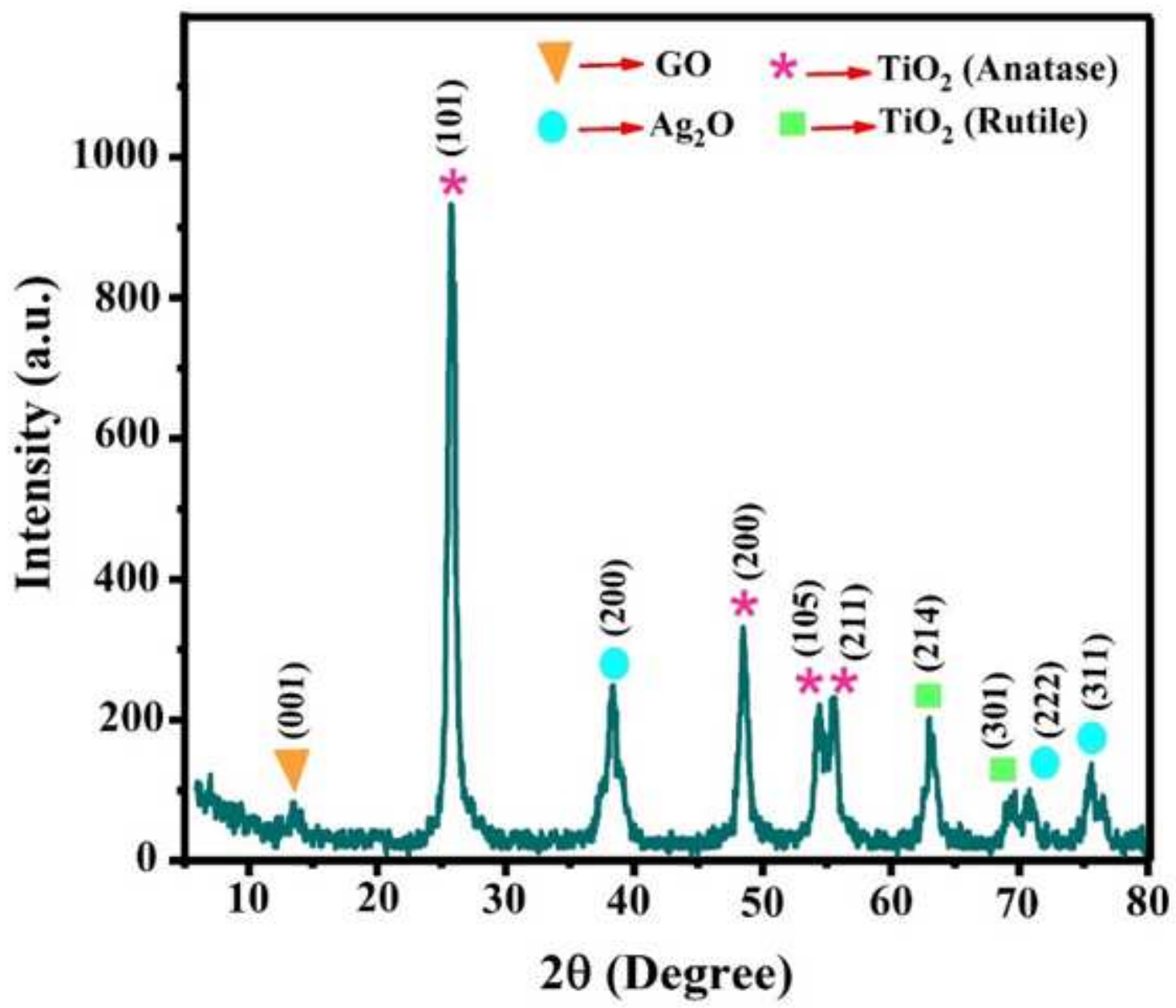

Figure 2

XRD pattern of Ag20/GO/TiO2 composite nanoparticles. 


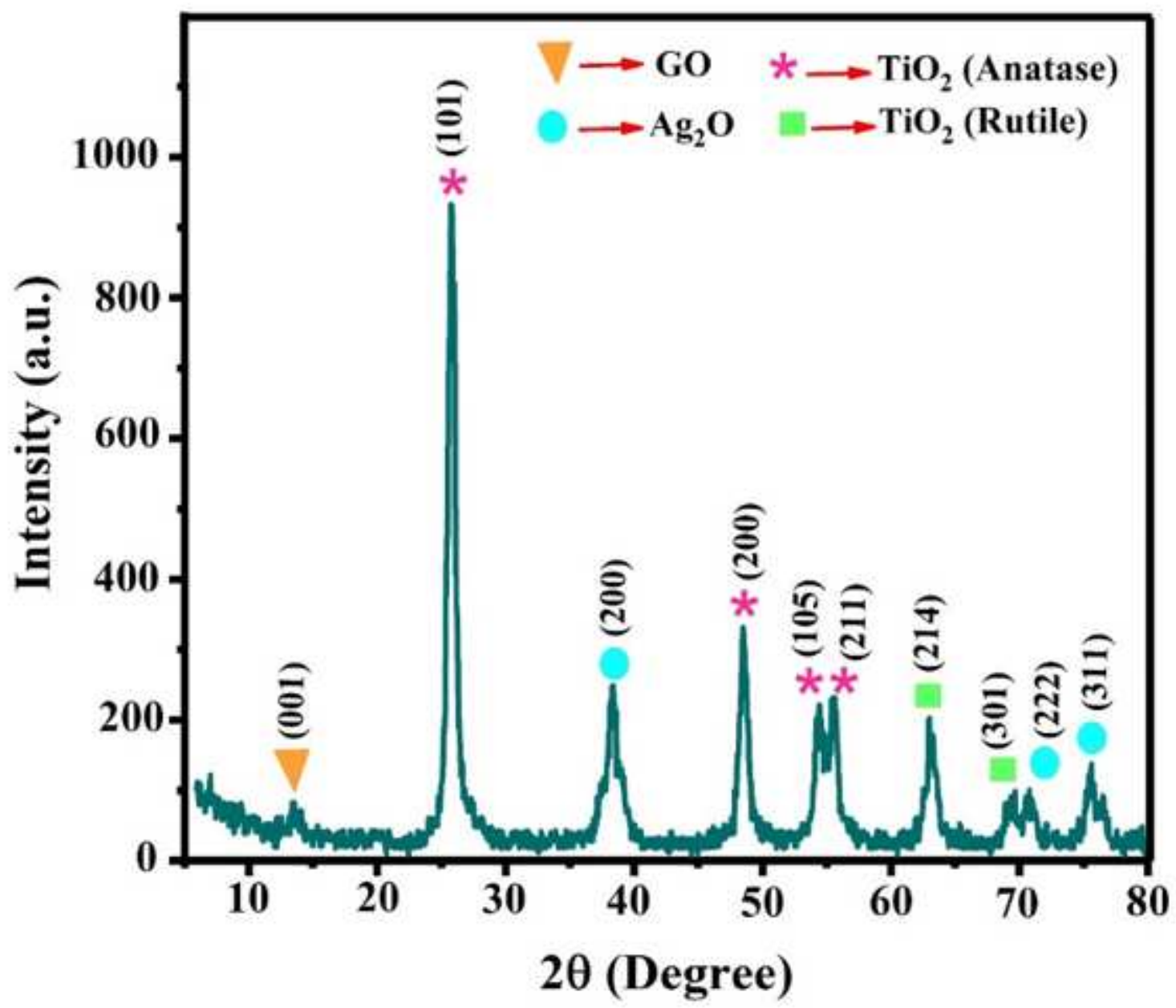

Figure 2

XRD pattern of Ag20/GO/TiO2 composite nanoparticles. 


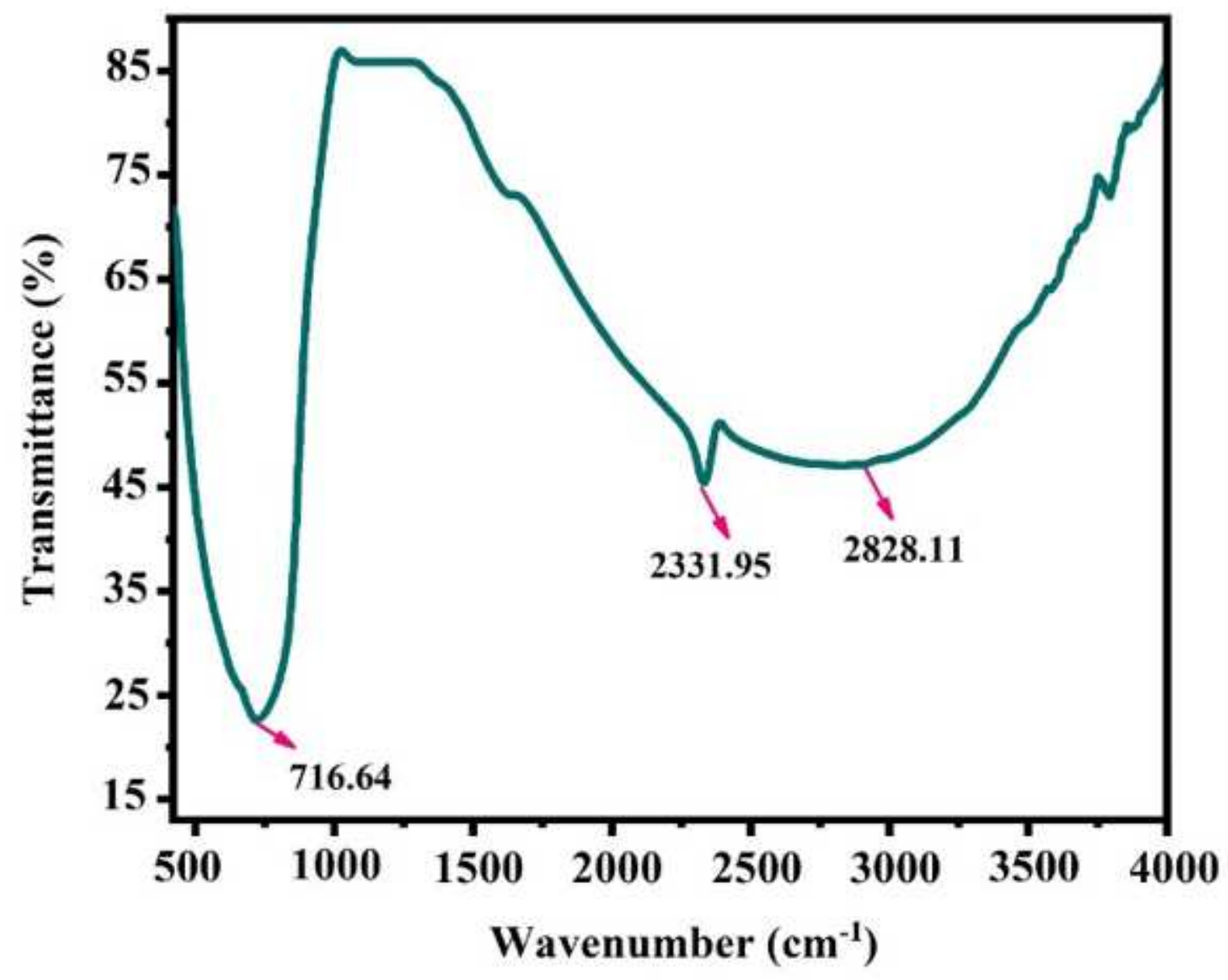

Figure 3

FTIR pattern of Ag2O/GO/TiO2 composite nanoparticles. 


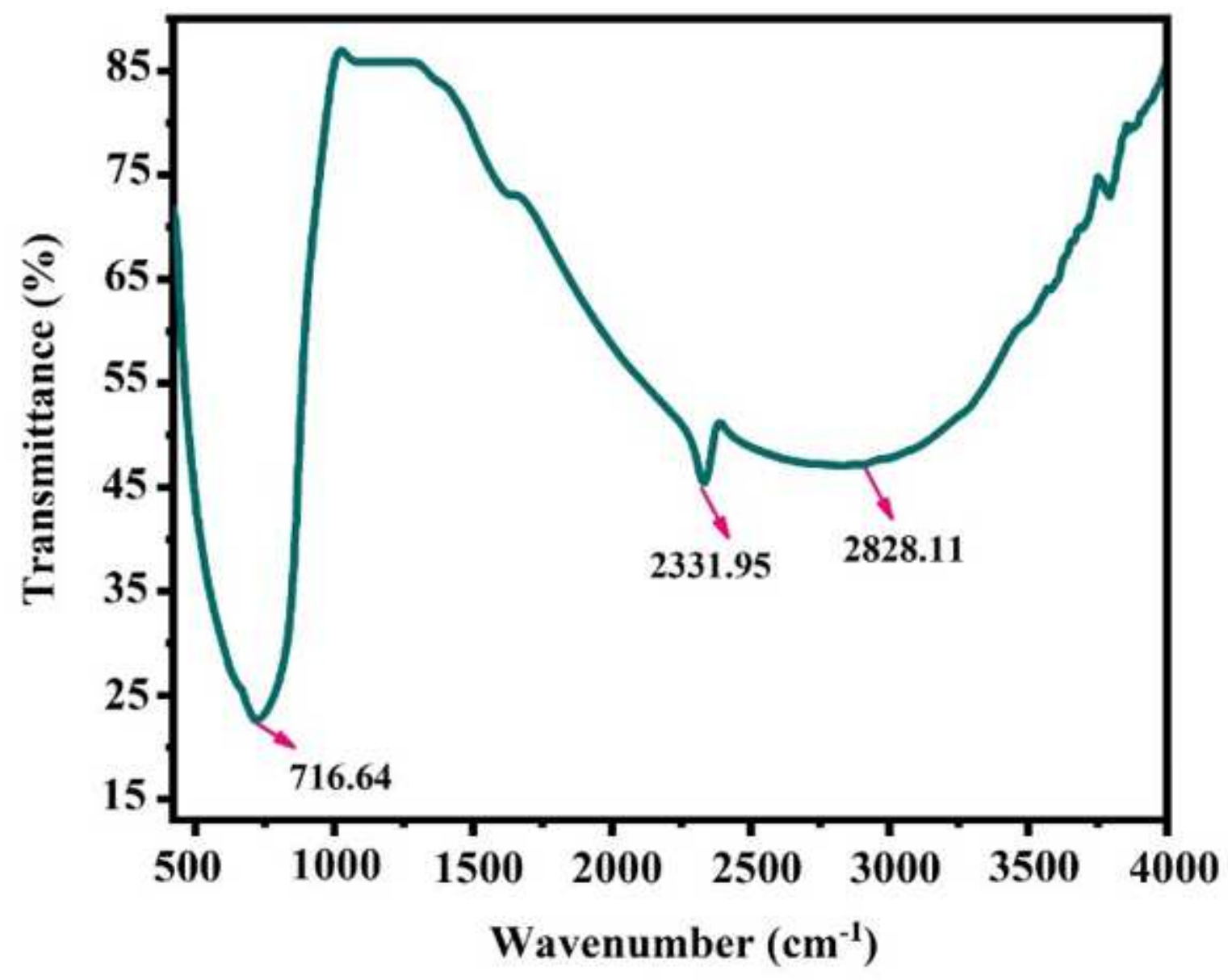

Figure 3

FTIR pattern of Ag2O/GO/TiO2 composite nanoparticles. 

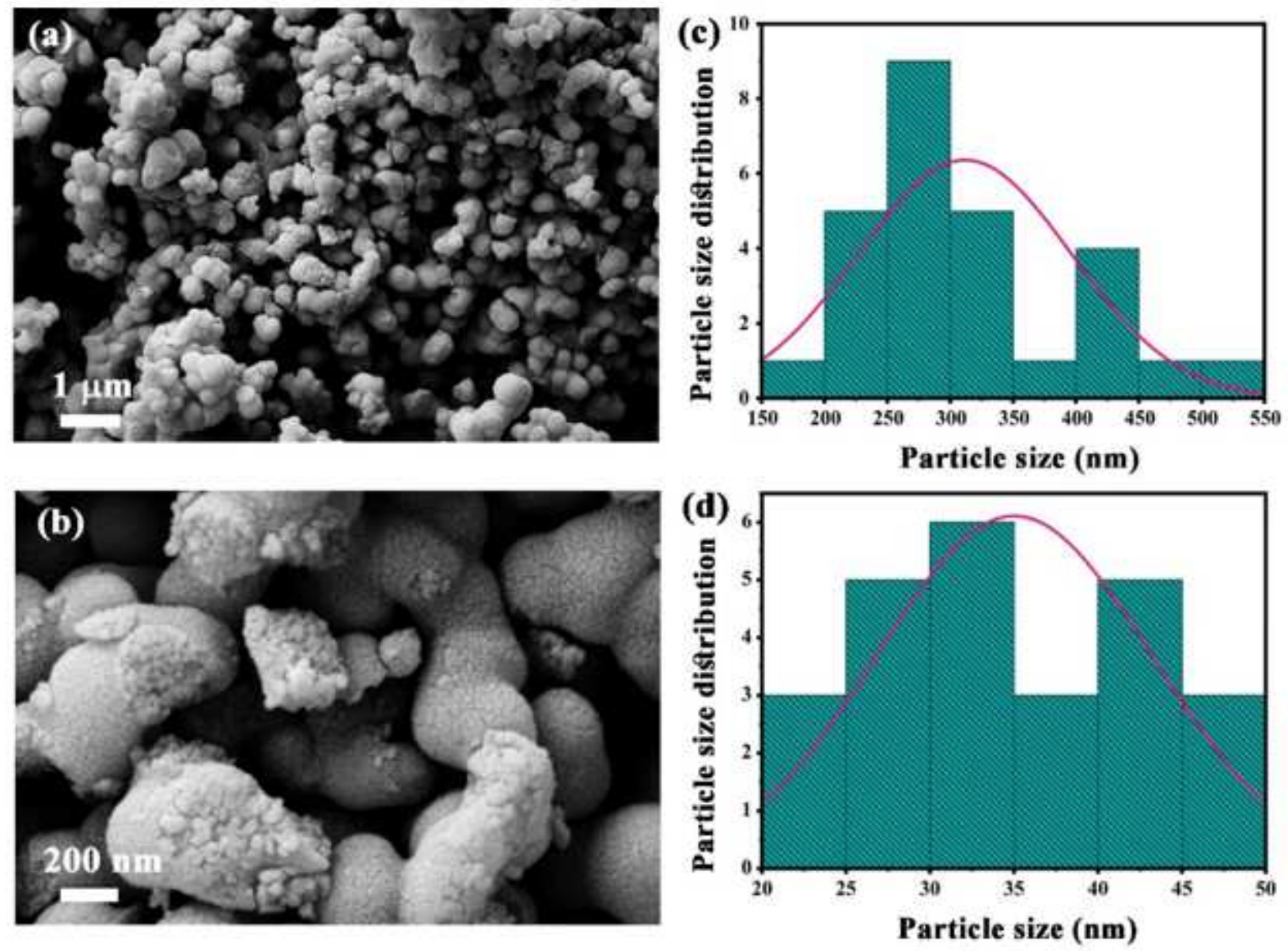

Figure 4

$(a, b)$ Typical FESEM images and (c, d) the corresponding histograms of particle size for Ag20/GO/TiO2 composite nanoparticles. 

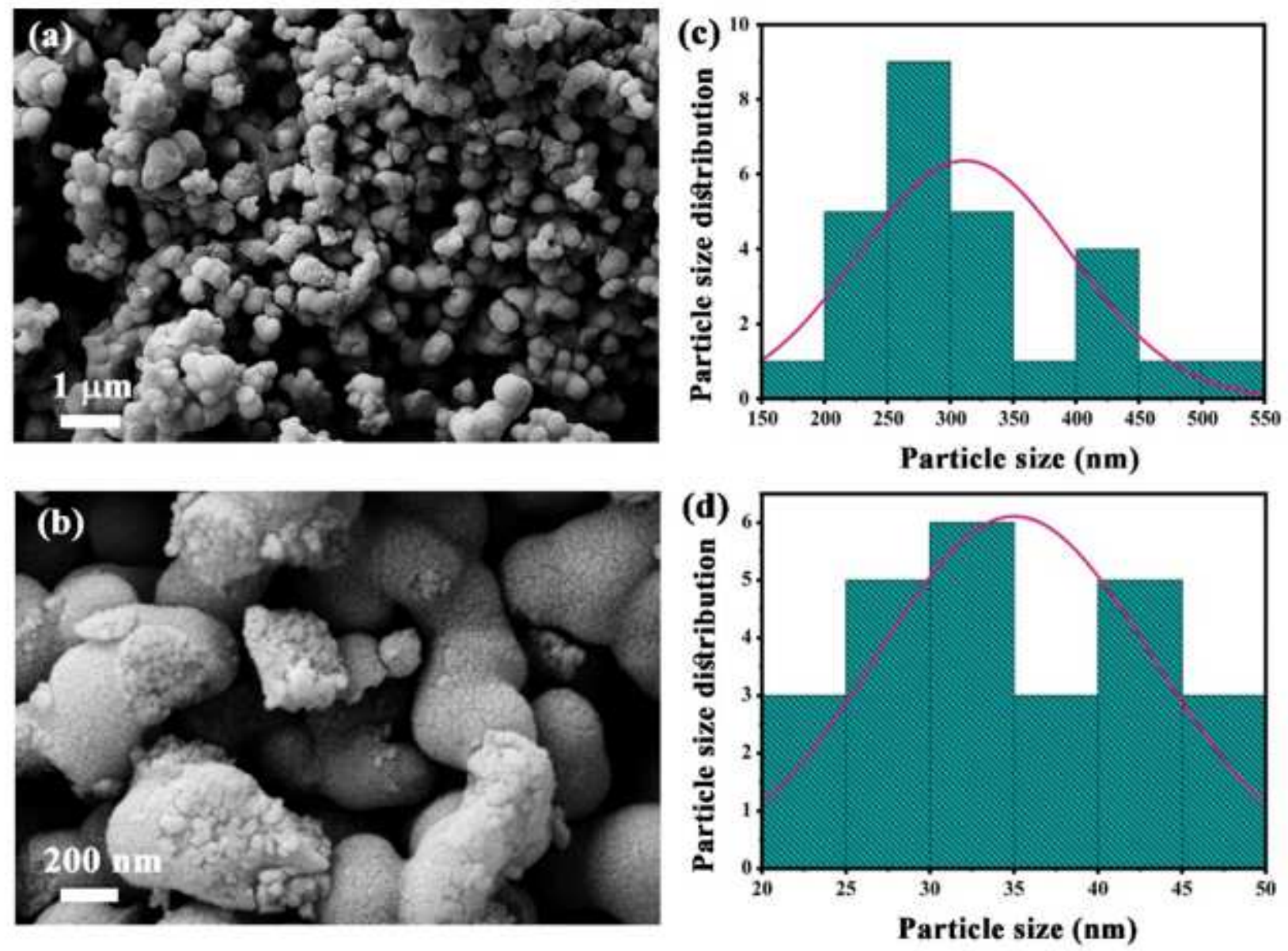

Figure 4

$(a, b)$ Typical FESEM images and (c, d) the corresponding histograms of particle size for Ag20/GO/TiO2 composite nanoparticles. 

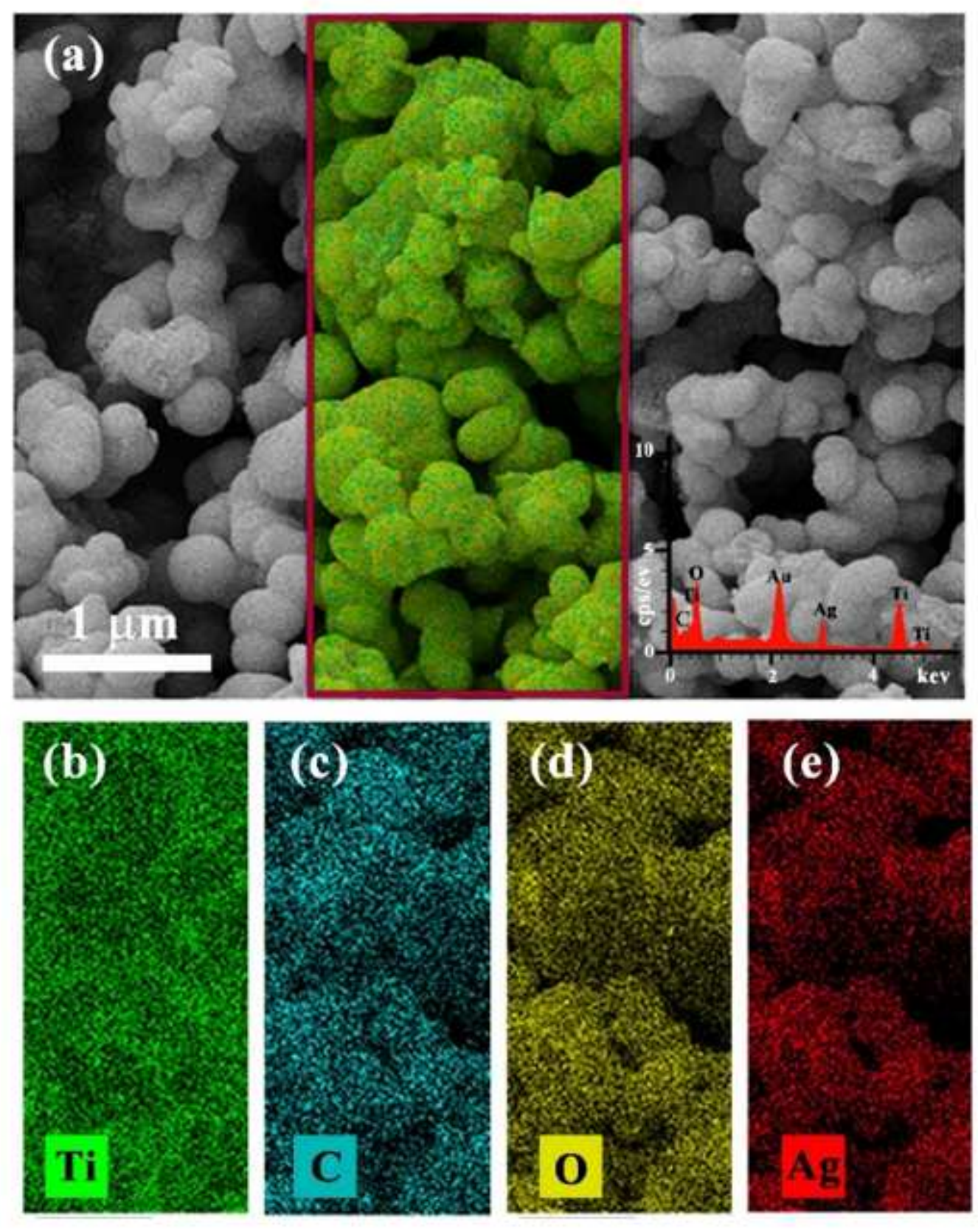

Figure 5

(a) FESEM image; Inset: corresponding EDS spectrum, and (b-e) EDS mappings of Ag20/GO/TiO2 composite nanoparticles. 

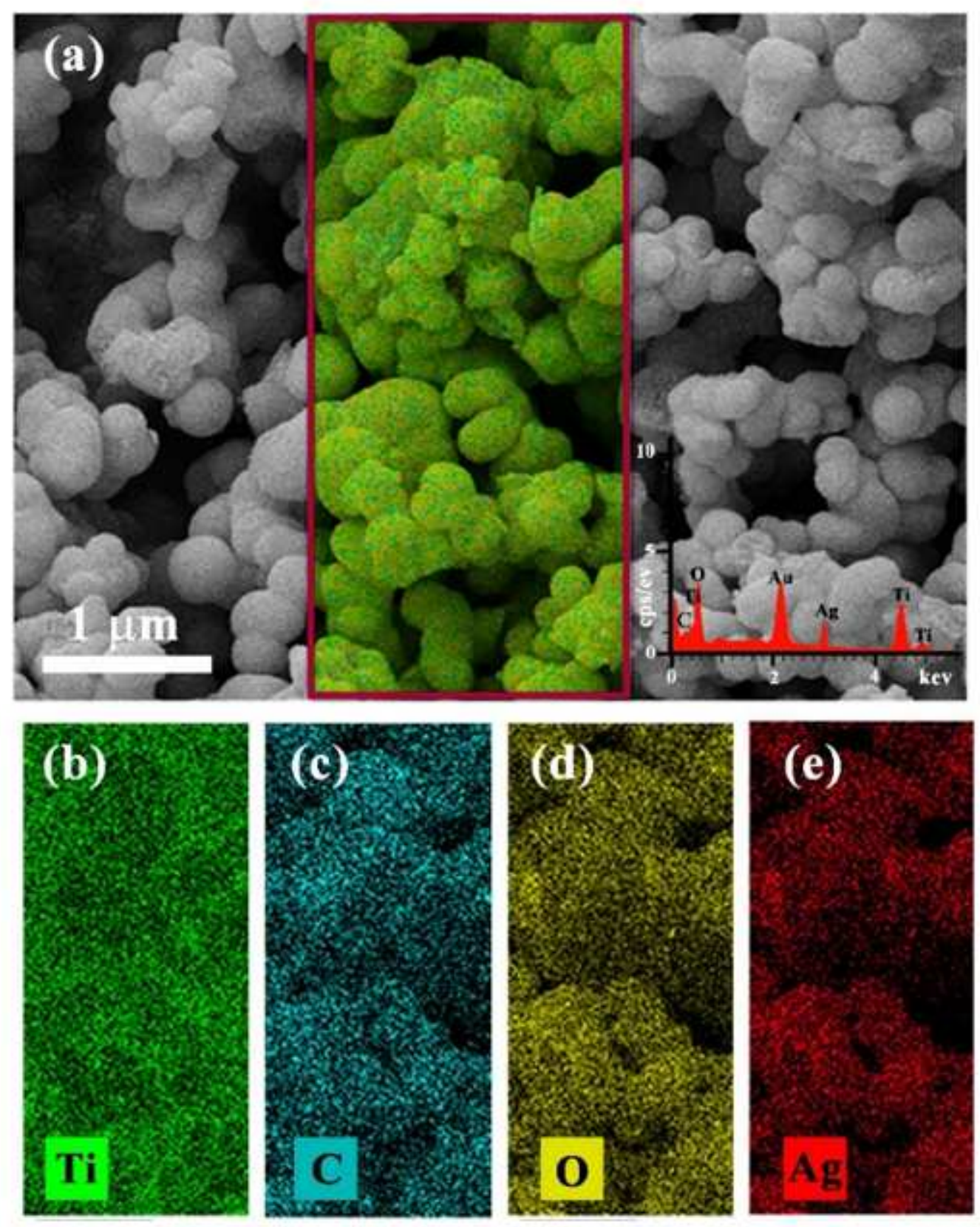

Figure 5

(a) FESEM image; Inset: corresponding EDS spectrum, and (b-e) EDS mappings of Ag20/GO/TiO2 composite nanoparticles. 


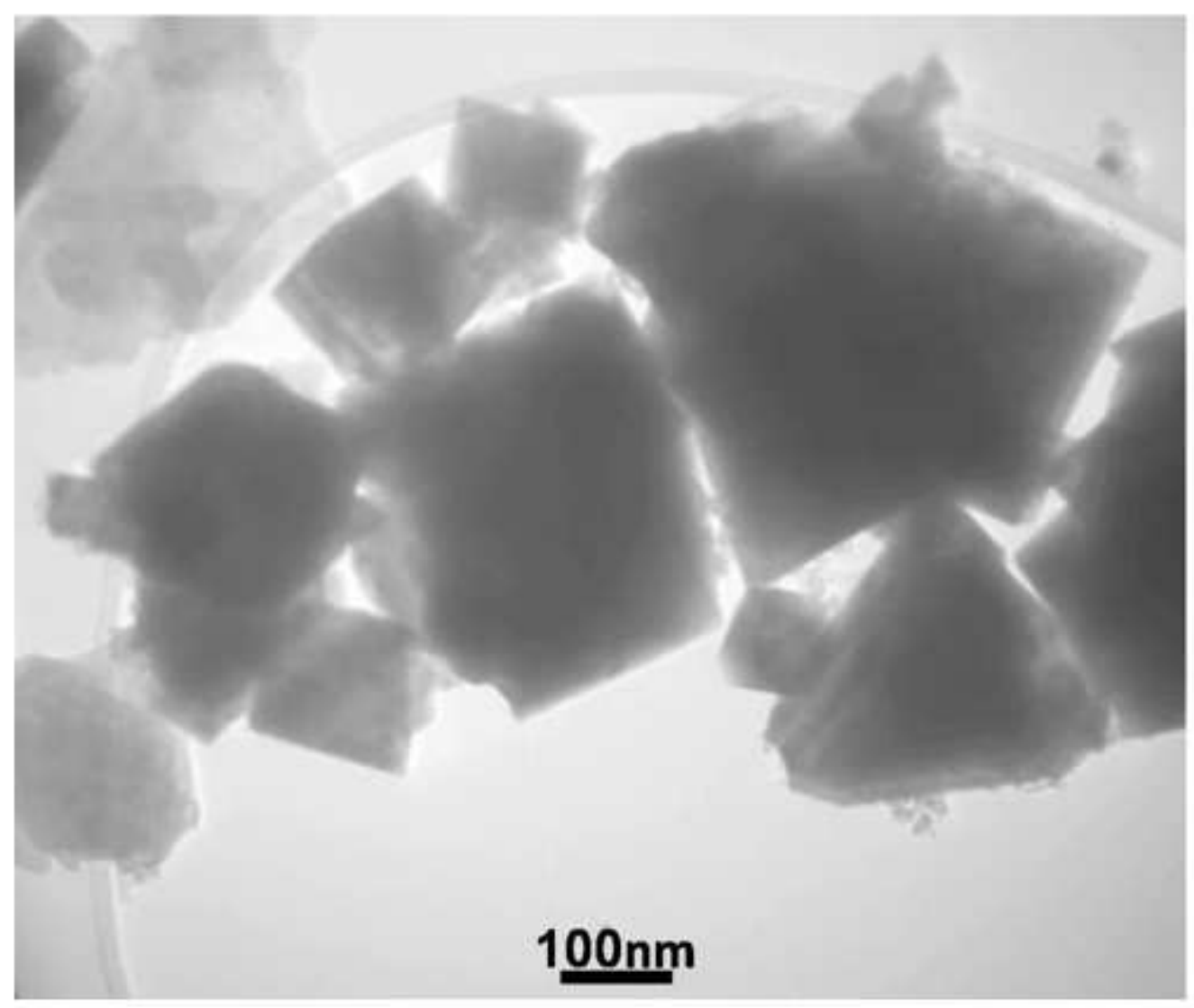

Figure 6

TEM image of Ag20/GO/TiO2 composite nanoparticles. 


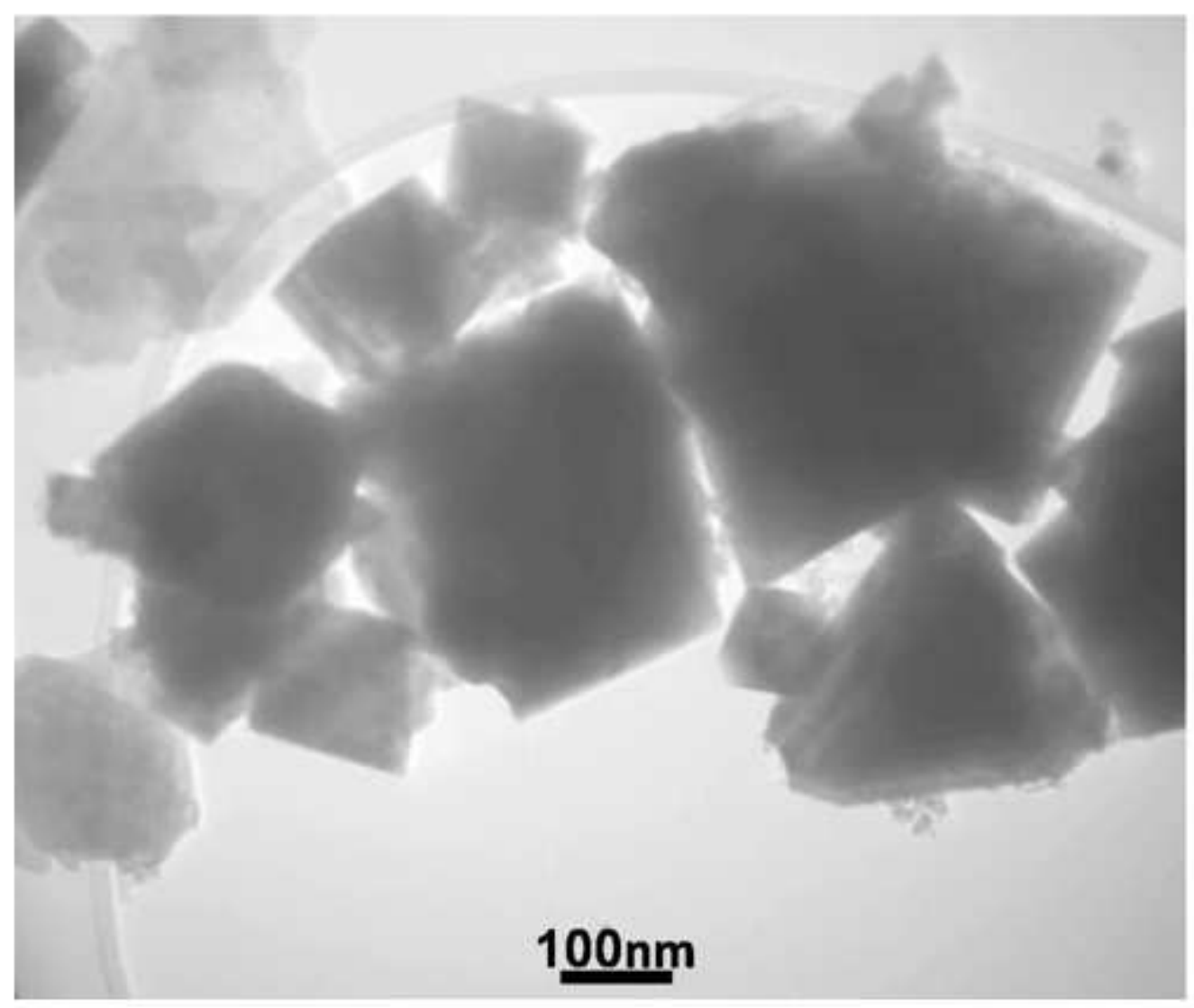

Figure 6

TEM image of Ag20/GO/TiO2 composite nanoparticles. 

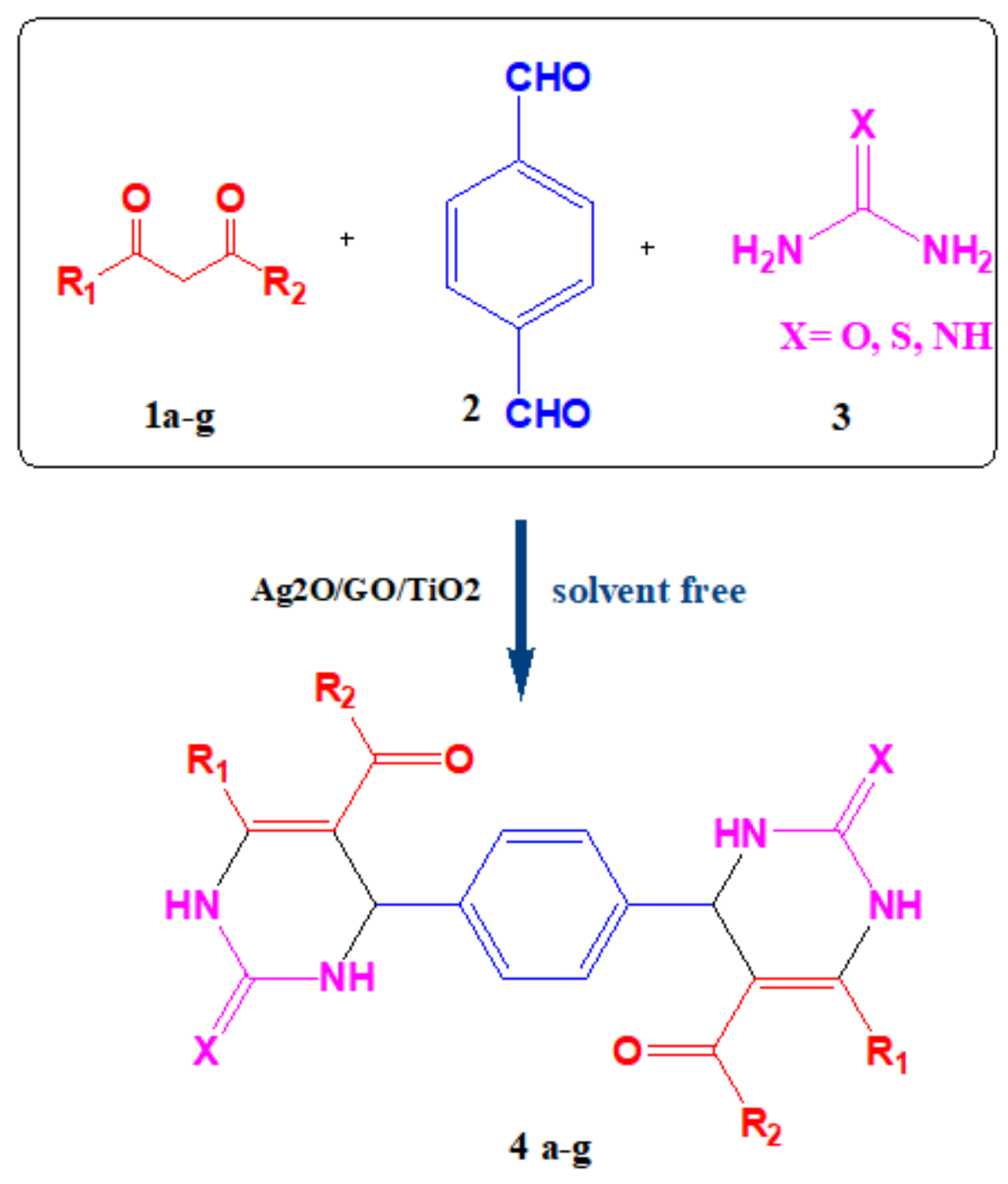

Figure 7

Scheme 1: One pot preparation of bis (dihydropyrimidon) derivatives catalyzed by Ag20/GO/TiO2 

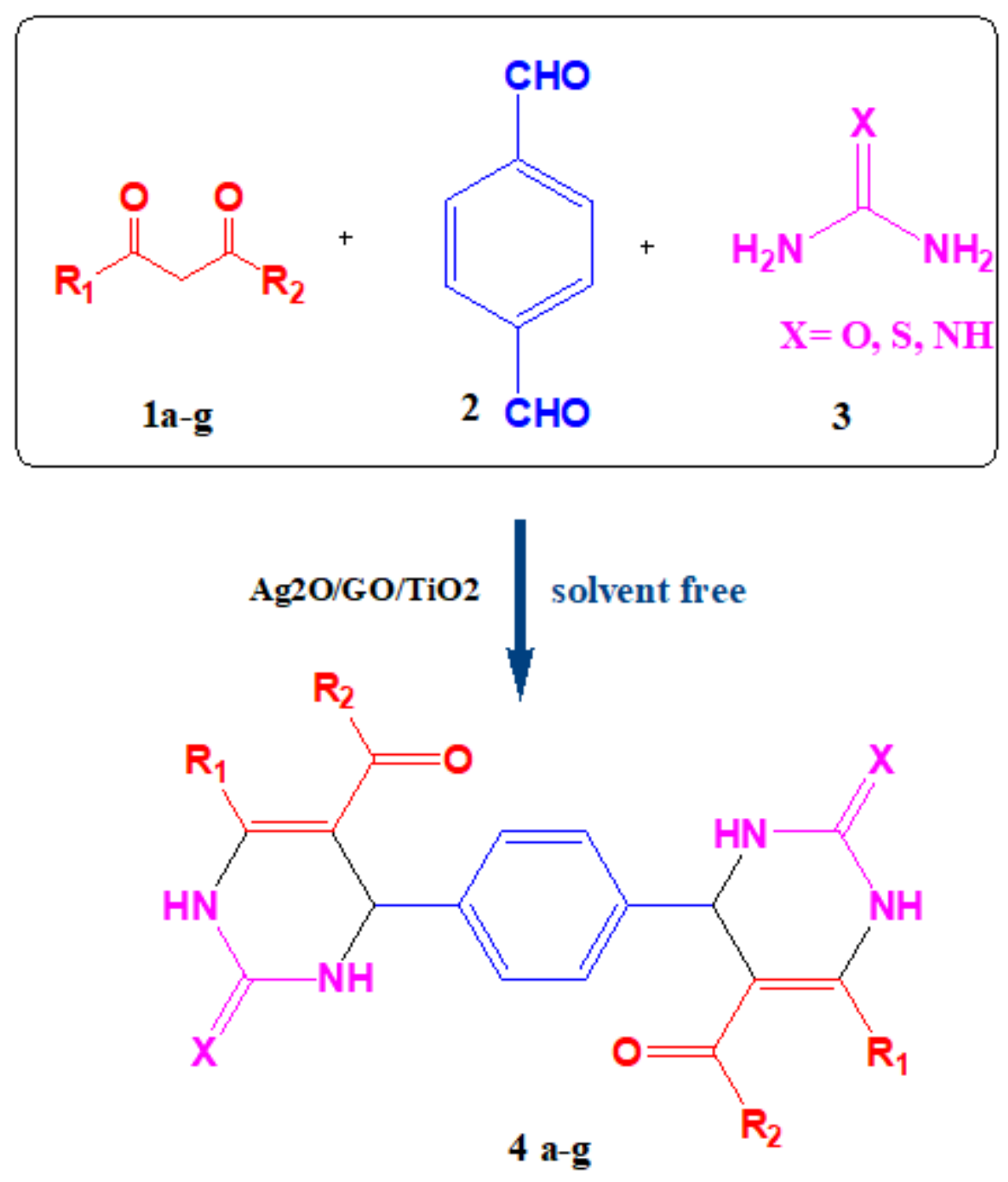

Figure 7

Scheme 1: One pot preparation of bis (dihydropyrimidon) derivatives catalyzed by Ag20/GO/TiO2<smiles>[R][R]1cccc(C=O)c1</smiles>

\section{Figure 8}

Scheme 2: One pot preparation of tetrahydro-4H-chromene derivatives catalyzed catalyzed by Ag2O/GO/TiO2 


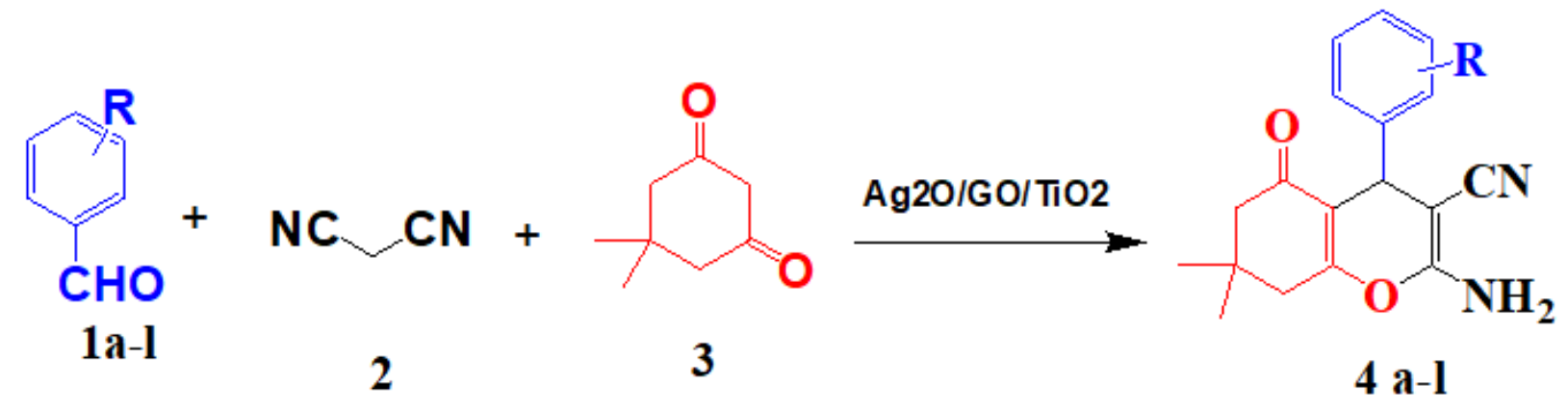

Figure 8

Scheme 2: One pot preparation of tetrahydro-4H-chromene derivatives catalyzed catalyzed by Ag2O/GO/TiO2 